\title{
EL EJERCICIO DE LA INICIATIVA LEGISLATIVA DE LAS COMUNIDADES AUTÓNOMAS ANTE EL GOBIERNO DE LA NACIÓN. SINGULARIDAD, DÉFICITS Y PROPUESTAS DE LEGE FERENDA
}

DAVID PARRA GÓMEZ 


\section{SUMARIO}

I. INTRODUCCIÓN. II. LO QUE EL DERECHO DICE AL RESPECTO:

2.1 La fase autonómica. Formulación articulada o no articulada del impulso correspondiente por la Asamblea de la Comunidad Autónoma. 2.2 La fase estatal y la actuación (o no actuación) del Gobierno central: A) Marco normativo. B) La asunción, en su caso, del impulso autonómico por parte del Gobierno: el «pase previo» del Consejo de Ministros. C) Excursus: ventajas e inconvenientes que puede comportar esta modalidad de iniciativa autonómica. Consideraciones sobre la supuesta preeminencia de la iniciativa legislativa del Gobierno. III. LO QUE EL DERECHO NO DICE. LOS HECHOS COMO «PASIVO» DE ESTA FIGURA: 3.1 Una causa que todavía pertenece al terreno del Derecho: sobre el despropósito que supone el que a una facultad atribuida por la Constitución a las Asambleas legislativas de las Comunidades Autónomas no le siga procedimiento alguno. 3.2 Y dos consecuencias de tal despropósito: A) Una secuela imposible de evitar: el desentendimiento prácticamente total del Gobierno de la Nación. B) Y una práctica disfuncional ya comprobada: la utilización desviada de esta figura con propósitos distintos de los que se le suponen. Recurso al «método del caso». IV. IDEAS PARA UNA PROPUESTA DE LEGE FERENDA. LA NECESIDAD DE IMPONER UNAS MÍNIMAS OBLIGACIONES AL GOBIERNO CENTRAL IMPULSADO POR ESTA VÍA. V. BIBLIOGRAFÍA. 


\title{
EL EJERCICIO DE LA INICIATIVA LEGISLATIVA DE LAS COMUNIDADES AUTÓNOMAS ANTE EL GOBIERNO DE LA NACIÓN. SINGULARIDAD, DÉFICITS Y PROPUESTAS DE LEGE FERENDA
}

\author{
DAVID PARRA GÓMEZ* \\ Profesor Asociado de la Universidad de Murcia
}

\section{INTRODUCCIÓN}

En toda forma de Estado compuesto, la participación de los territorios autónomos (Estados, regiones...) en la adopción de las decisiones generales por parte de las instituciones centrales ha adquirido un carácter esencial al hacer posible, por un lado, la consideración y protección de los diferentes intereses territoriales, y al asegurar, por otro, la conveniente integración de los mismos en el conjunto estatal. La Constitución española de 1978 ha optado por un modelo de Estado territorialmente compuesto, el Estado autonómico, y si bien la propia indefinición de muchas de sus líneas fundamentales y su correlativa condición abierta han provocado que su texto acoja con cierta ambigüedad algunas formas de participación de las Comunidades Autónomas en la formación de la voluntad nacional, ello no ha impedido que entre esas formas se encuentre con toda nitidez la facultad de iniciar leyes estatales prevista en el apartado segundo del artículo 87 de dicha norma.

\footnotetext{
* Doctor en Derecho. Profesor Asociado del Departamento de Fundamentos del Orden Jurídico y Constitucional (Área de Derecho Constitucional) de la Universidad de Murcia. Facultad de Derecho. Campus de La Merced. 30001 Murcia. Correo electrónico: david.parra@um.es
} 
Visto desde la Historia, el reconocimiento de la iniciativa legislativa autonómica ha supuesto una importante novedad en nuestra ya larga trayectoria constitucional. Tradicionalmente, la iniciativa legislativa ha tenido en nuestro Derecho una configuración dualista (la iniciativa correspondía al Rey y a las Cortes en las Constituciones de 1812, 1837, 1845, 1869 y 1876, o a las Cortes y al Gobierno en la Constitución de 1931), salpicada, no obstante, de algún período monista en el que se estableció un monopolio en favor del Monarca (Estatuto Real de 1834). Pero, por lo que aquí nos importa, ni siquiera el Proyecto de Constitución Federal de 1873 o la Constitución de 1931, pese a contemplar modelos territoriales compuestos, reconocieron a los Estados miembros o a las regiones constitutivas del Estado integral, respectivamente, la potestad de iniciativa legislativa ante el Parlamento nacional. Tal reconocimiento se realiza ahora por primera vez, y se realiza, además, adoptando un criterio de doble opción sin precedentes en otros sistemas descentralizados, ya que pone a disposición de las Asambleas autonómicas dos posibilidades de iniciativa formalmente distintas: la de solicitar del Gobierno la adopción de un proyecto de ley, y la de remitir a la Mesa del Congreso una proposición de ley.

La atención científica a esta novedad no se corresponde, sin embargo, con su interés. Así, el más somero examen de la bibliografía existente muestra que los excelentes trabajos sobre la potestad de iniciativa legislativa con los que contamos se han ocupado preferentemente de cuestiones relacionadas con la facultad de iniciativa en su condición general o en su ejercicio por el Gobierno o por los diputados y senadores como supuestos más comunes. Incluso sobre la iniciativa legislativa popular no falta literatura que la analice. Por otra parte, los escasos trabajos que tratan la iniciativa legislativa autonómica se centran casi exclusivamente en la segunda de las vías acogidas por el artículo 87.2 CE, la remisión de proposiciones de ley a la Mesa del Congreso ${ }^{1}$, sin que prácticamente se haya llevado a cabo ningún comentario teórico que trate de dar sentido, hacer la crítica y elaborar unas ciertas garantías al estímulo autonómico de la iniciativa legislativa del Gobierno.

1 Vid., Merino Merchán, J.F. (1984): «La potestad de iniciativa legislativa de las Comunidades Autónomas», en Organización territorial del Estado (Comunidades Autónomas), Madrid, Instituto de Estudios Fiscales; Mollinedo Chocano, J.J. (1998): «La iniciativa legislativa de las Comunidades Autónomas», en El procedimiento legislativo: V Jornadas de Derecho Parlamentario, Madrid, Congreso de los Diputados; Lavilla Rubira, J.J. (1990): «Las proposiciones de ley remitidas por las Comunidades Autónomas al Congreso de los Diputados», en Revista Española de Derecho Constitucional, núm. 28; GARCía MarTínez, M.A. (1998): «Las participación de las Comunidades Autónomas en el procedimiento legislativo estatal», en Revista de la Facultad de Derecho de la Universidad Complutense de Madrid, núm. 22; y Navarro RuIz, J.C. (2014): «La iniciativa legislativa de los parlamentos autonómicos ante el parlamento estatal», en Representación política y parlamentarismo multinivel, Valencia, Tirant lo Blanch, núm. 59. 
El análisis del ejercicio de la facultad autonómica de solicitar proyectos de ley al Gobierno, objeto del presente estudio, abre todo un panel de cuestiones a tratar, algunas más sustantivas, como conocer el por qué de dicha previsión (¿para qué estimular la puesta en marcha de la ley ante un órgano que no es un legislador o, al menos, no es el legislador cuya actividad se persigue?, ¿qué ventajas puede tener esta forma de plantear — de abrir — la figura que nos ocupa?), y otras estrictamente procedimentales, principalmente referidas a la tramitación, en el seno del Gobierno, de las solicitudes de proyectos remitidas por los parlamentos autonómicos, a todas las cuales trataremos de ir dando respuesta. Con el fin de ordenar todas estas cuestiones, será útil indicar que la actuación de la iniciativa autonómica ante el Gobierno que el artículo 87.2 CE atribuye a las Asambleas de las Comunidades Autónomas se articula a través de tres fases claramente diferenciadas, de las cuales tan sólo las dos primeras pertenecen, en sentido estricto, a dicho instituto:

La primera de estas fases tiene lugar en el seno de los parlamentos autonómicos de acuerdo con lo previsto en sus respectivos reglamentos parlamentarios, y se concreta en la aprobación por tales cámaras de la remisión al Gobierno de una solicitud o propuesta de proyecto de ley.

La segunda fase se desarrolla en el seno del Gobierno, el cual, si decide discrecionalmente atender la solicitud remitida por una Asamblea autonómica, iniciará el procedimiento de elaboración, aprobación y posterior remisión al Congreso de los Diputados del proyecto de ley previsto en nuestro ordenamiento jurídico.

Es verdad que, además, dicho proceso, caso de llegar hasta ahí, incluye una tercera y última fase la cual habrá de tener lugar en las Cortes Generales con sujeción a lo previsto por los Reglamentos del Congreso y del Senado y deberá concretarse en la tramitación del proyecto de ley presentado a través del procedimiento legislativo previsto al efecto, a resultas del cual puede aquél devenir en ley estatal. Pero es obvio que el estudio de este tercer estadio pertenece ya al propio de la tramitación común a cualquier proyecto de ley, sin singularidades que tengan que ver con la figura que estamos considerando, y, por lo tanto, excede claramente del objeto de este trabajo.

\section{LO QUE EL DERECHO DICE AL RESPECTO}

\subsection{La fase autonómica. Formulación articulada o no articulada del impulso correspondiente por la Asamblea de la Comunidad Autónoma}

En relación con la primera de las fases antes mencionadas, la mayoría de los reglamentos parlamentarios autonómicos asimilan la tramitación para el ejerci- 
cio de la iniciativa ante el Gobierno a la seguida para la actuación de la otra vía prevista en el artículo 87.2 CE, la remisión de proposiciones de ley al Congreso, razón por la cual no nos detendremos en ella salvo para destacar dos importantes consecuencias de aquella asimilación o, para ser más exactos, realizar dos obligadas puntualizaciones:

En primer lugar, que las reglas procedimentales que se aplican para que las Asambleas adopten la decisión que comentamos serán las propias del procedimiento legislativo común u ordinario previstas en aquellos reglamentos para elaborar todo tipo de proposiciones de ley, y a cuyo través aquellas cámaras aprueban sus propias leyes en sus respectivos ámbitos de competencia, aunque con algunas especialidades procedimentales, entre las que cabe destacar, por ser también de aplicación al caso que nos ocupa, la aprobación de la iniciativa mediante mayoría absoluta del Pleno donde así esté establecido².

$Y$, en segundo término, que a pesar de que, en principio, la previsión del artículo 87.2 CE puede ser cubierta por la Asamblea autonómica, o bien enviando un texto articulado para que el Gobierno, si lo considera oportuno, decida sobre su eventual remisión al Congreso de los Diputados como proyecto de ley, o bien remitiéndole una mera solicitud o comunicado en el que exprese su interés por la regulación de una determinada materia, la posterior regulación reglamentaria de dicha alternativa aboca (con las solas dos excepciones que enseguida comentamos) a la imposición casi generalizada de que lo hay que remitir al Gobierno es un texto articulado, bien que esa imposición provenga, como acabamos de ver, de la regulación realizada por los citados reglamentos y no de los términos del precepto constitucional mencionado, lo que la priva de un valor absoluto ${ }^{3}$.

Existen, no obstante, como arriba advertimos, dos reglamentos parlamentarios autonómicos que excepcionan o suavizan esta imposición, en los siguientes términos:

2 Vid., artículos 172.1 del Reglamento del Parlamento de Andalucía, 219.2 del Reglamento de las Cortes de Aragón, 163 del Reglamento de la Junta General del Principado de Asturias, 185.3 del Reglamento del Parlamento de las Islas Baleares, 169.2 del Reglamento de las Cortes de Castilla-La Mancha, 131.1 del Reglamento de las Cortes de Castilla y León, 193.1 del Reglamento de la Asamblea de Extremadura, 193 del Reglamento del Parlamento de Cantabria; 163.1 del Reglamento del Parlamento de Galicia, 156.1 del Reglamento del Parlamento de La Rioja, 176.1 del Reglamento de la Asamblea de Madrid, 212.1 del Reglamento del Parlamento de Navarra, 170.1 del Reglamento de las Cortes Valencianas y 170.1 del Reglamento de la Asamblea Regional de Murcia.

3 Así se deriva, por ejemplo, de los artículos 154.2 a) del Reglamento del Parlamento de Canarias, 74.3 del Reglamento de la Asamblea de la Ciudad de Ceuta, 177 del Reglamento de la Asamblea de Madrid y 72.2 del Reglamento de la Asamblea de la Ciudad de Melilla. 
a) El primero de ellos es el Reglamento de la Asamblea Regional de Murcia, cuyo artículo 147 precisa en su punto segundo que la Asamblea puede solicitar del Gobierno "...la presentación del oportuno proyecto de ley, cuyo texto se incluirá formulado en un anexo», es decir, incluyendo un texto articulado, lo que supondría acogerse a la regla más común, no obstante lo cual en su punto tercero abre también a la Asamblea la posibilidad de que indique simplemente al Gobierno «...con exactitud el objeto sobre el que deba versar el proyecto de ley, pero confiando a dicho órgano su formulación». En consonancia con esta doble posibilidad, el artículo 148 establece, asimismo, dos procedimientos distintos para que la Asamblea murciana llegue a cada uno de tales resultados, con diferencias de trato, incluso, que no siempre se justifican. Decimos esto porque, en el primer caso (adopción de un texto articulado), las normas procedimentales a utilizar son, según el artículo 148.1, las que el Reglamento establece para la elaboración y adopción parlamentaria de los proyectos y proposiciones de ley: «...tanto los requisitos de iniciativa — dice su texto- como los trámites de enmienda, audiencia, debate y votación del texto articulado que deba proponerse (al Gobierno central), se ajustarán a lo que este Reglamento dispone para la elaboración de los proyectos y proposiciones de ley...», a lo cual añade, acto seguido, una referencia a los sujetos dotados de capacidad para iniciar tal proceso cuyo contenido debemos retener a fin de poder cotejarlo después con la otra posibilidad conocida: «...admitiéndose dice-para iniciarlo cualquiera de las vías previstas en el artículo 118».

Atendida, por tanto, esta remisión y visto el contenido del citado artículo 118 , podrán iniciar en la Asamblea el proceso de aprobación de un borrador de proyecto de ley a enviar al Gobierno, cuando ese borrador se materialice en un texto articulado, el Consejo de Gobierno, el portavoz de un grupo parlamentario de los constituidos al inicio de la legislatura, un diputado con la firma de otros tres, así como los municipios y las comarcas, amén de los ciudadanos de la Región de Murcia (conforme a lo que determina la Ley 9/1984, de 22 de noviembre, reguladora de la iniciativa legislativa popular, de los Ayuntamientos y Comarcas).

Sin embargo, en el segundo caso, en el que no va a haber un texto articulado, el procedimiento es el dispuesto en el Reglamento para las mociones porque así lo afirma ahora el artículo 148.2: «... la iniciativa — advirtamos aquí su mención expresa-, enmienda, audiencia, debate y votación...se realizará conforme a lo dispuesto para las mociones y siempre en el Pleno». Ello comporta, por tanto, un reenvío a los artículos 187 y 188 del Reglamento parlamentario murciano donde esa regulación de las mociones está ubicada y, en consecuencia, si nos atenemos a los aspectos que afectan a la capacidad para iniciarlas, resultaría que en este caso (sugerencia sin adjuntar texto), tan sólo podrían iniciar el proceso que nos ocupa 
(artículo 187.1) «un Grupo Parlamentario o...un Diputado con la firma de otros dos», diferencia de trato con los proyectos sí articulados que difícilmente se entiende y que, en cierto modo, habría que atribuir a una mala técnica legislativa. Sí cabe aceptar que la distinta formalización de ambos supuestos, articulada en un caso y no en otro, comporte diferencias respecto del modo de trabajarlos, pero no se explica con igual facilidad que tales distingos afecten también a los sujetos capaces de abrir el proceso.

A nuestro juicio, la cuestión habría que solventarla realizando una interpretación expansiva del artículo 148.2 según la cual, olvidando la literalidad con la que el citado precepto se refiere también a la iniciativa, pasáramos a considerar que todos los sujetos con capacidad para estimular la iniciativa del Gobierno de la Nación mediante el depósito de un proyecto articulado de ley estatal la tienen, asimismo (quien puede lo más, puede lo menos), para impulsar esa iniciativa cuando se trate de una sugerencia y no de un texto articulado.

b) Por su parte, en fin, como segunda de aquellas dos normaciones con matices que anunciábamos, el Reglamento del Parlamento Vasco precisa (artículo 230) que las "proposiciones no de ley» a través de las cuales se promueve la iniciativa ante el Gobierno se tramitarán conforme al régimen general previsto para las proposiciones no de ley (artículos 172-177), salvo que —añade- las iniciativas presentadas incorporen una propuesta articulada, en cuyo caso se tramitarán de acuerdo con el procedimiento legislativo ordinario, lo cual abre una doble posibilidad muy similar a la del caso murciano.

En consecuencia — como allí, y sin que sea preciso repetir aquí la idéntica censura que dicha regulación nos merece-, podrán iniciar el procedimiento para la aprobación del estímulo de la iniciativa gubernamental que incorpore una propuesta articulada un grupo parlamentario, un parlamentario con la firma de otros cuatro miembros de la Cámara, las Juntas Generales de los territorios históricos y los electores en los términos regulados en la Ley de Iniciativa Legislativa Popular (artículo 147); mientras que las meras proposiciones no de ley, sin texto articulado, sólo podrán ser presentadas por los grupos parlamentarios (artículo 172).

\subsection{La fase estatal y la actuación (o no actuación) del Gobierno central}

\section{A) Marco normativo}

Llegada la solicitud del parlamento autonómico al Gobierno de la Nación, las posibilidades que se abren son, obviamente, dos: el Gobierno puede, sencillamente, archivar (si es que lo hace, lo cual no es ni siquiera tan seguro a la 
vista de nuestras indagaciones) dicho documento, puesto que el Derecho no le obliga a más, o puede hacerse cargo de la conveniencia o inconveniencia del asunto propuesto optando por debatir sobre su eventual conversión en proyecto de ley, iniciativa que a partir de aquí pasaría a ser del propio Gobierno. Por razones más que evidentes, la primera de ambas posibilidades (el Gobierno se desentiende de tal escrito) no es que no tenga interés; lo tiene y mucho, y de ello hablaremos más tarde, pero lo que no posee es un régimen procesal que, en este caso, sería tan absurdo como vacío de contenido. Así pues, es a la segunda de esas posibilidades — nada frecuente en la práctica, por cierto- a la que van referidas las alusiones al «marco normativo» que hacemos a continuación.

El ejercicio de la iniciativa legislativa del Gobierno, tanto si la misma procede de su propio impulso como si proviene — cual es el caso aquí- del impulso de una Comunidad Autónoma, viene regulado fundamentalmente por el artículo 88 de la Constitución, que se limita a establecer que: «Los proyectos de ley serán aprobados en Consejo de Ministros, que los someterá al Congreso acompañados de una exposición de motivos y de los antecedentes necesarios para pronunciarse sobre ellos», exigencias ambas que, obviamente, deben afectar también al caso que nos ocupa; y, en su desarrollo básico, por la Ley 6/1997, de 14 de abril, de Organización y Funcionamiento de la Administración General del Estado (LOFAGE) y por la Ley 50/1997, de 27 de noviembre, de Organización, Competencias y Funcionamiento del Gobierno (LG), la cual abandonó, acertadamente, el tratamiento procedimental unitario de la elaboración de los reglamentos y los anteproyectos de ley al establecer una regulación separada y distinta de ambos tipos normativos: la iniciativa legislativa del Gobierno, supuesto éste que es el que aquí nos atañe (artículo 22 LG), y el ejercicio de la potestad reglamentaria (artículos 23 y 24 LG).

Hasta 1997, el procedimiento para el ejercicio de la iniciativa legislativa del Gobierno establecido en desarrollo de aquella norma constitucional estaba regulado fundamentalmente en la Ley de Procedimiento Administrativo de 17 de julio de 1958 (Capítulo 1. ${ }^{\circ}$, Título VI, artículos 129 a 132), que trataba del procedimiento para la elaboración de disposiciones de carácter general y que, en lo que concierne a la elaboración de proyectos de ley, contenía un criterio de elaboración "difusa» similar al seguido en Alemania (en contraste con el modelo de elaboración "concentrada» más propio del área anglosajona) al establecer el artículo 129.1 que: "La elaboración de disposiciones de carácter general y de anteproyectos de ley se iniciarán por el Centro directivo correspondiente, con los estudios e informes previos que garanticen su legalidad, acierto y oportunidad de aquéllos». 
Siguiendo el modelo alemán mencionado ${ }^{4}$, el Consejo de Ministros aprobó mediante Acuerdos de sus respectivas fechas las «Instrucciones para la tramitación de asuntos del Consejo de Ministros y de la Comisión General de Subsecretarios», de 16 de noviembre de 1983, que fueron modificadas por Acuerdo de 9 de octubre de 1987 y sustituidas por las «Instrucciones para la tramitación de asuntos en los órganos colegiados del Gobierno (texto refundido)» de 9 de diciembre de 1989, a su vez derogadas por las vigentes «Instrucciones» de 26 de julio de 1996; a ellas hay que añadir el «Cuestionario de evaluación que deberá acompañarse a los proyectos normativos que se elevan al Consejo de Ministros», de 26 de febrero de 1990; y las «Directrices sobre la forma y estructura de los anteproyectos de ley», de 18 de octubre de 1991, que fueron derogadas por las vigentes «Directrices de técnica normativa» de 22 de julio de 2005. Documentos todos que afectan también a los textos producto del impulso de una Comunidad Autónoma, bien que con las adaptaciones que correspondan, y no digamos a aquellos otros supuestos en los que la Comunidad de que se trate haya preferido deferir al Gobierno de la Nación la concreta elaboración de dicho anteproyecto, ya que en este caso, como es obvio, todas estas directrices dirigidas a los órganos del Gobierno central pasarán a tener una relevancia aún mayor.

A lo anterior queda añadir, para completar nuestra referencia al marco normativo dentro del cual habrá de moverse el Gobierno si es que decide hacer suyo el impulso legislativo que le llega desde una Asamblea autonómica: que la Ley 30/2003, de 13 de octubre, sobre medidas para incorporar la valoración del impacto de género en las disposiciones que elabore el Gobierno, modificó el artículo 22.2 LG (elaboración de proyectos de ley) y añadió un segundo párrafo en el artículo 24.1.b) (elaboración de reglamentos) para exigir que se redacte para cada proyecto un «Informe sobre el impacto por razón de género»'; que el Real Decreto 1083/2009 reguló la inclusión de las memorias, estudios e informes que se contemplan en los artículos 22.2, 24.1.a) y 24.1.b), párrafo segundo LG en un único documento denominado "Memoria del análisis de impacto normativo», que deberá redactar el órgano o centro directivo proponente del proyecto normativo

${ }^{4}$ Puede encontrarse un interesante estudio comparado del modelo británico de redacción concentrada de los proyectos de ley y del ejemplo alemán de redacción difusa en MARTín CASALS, $\mathrm{M}$. y Viver Pi-Sunyer, C. (1990): «QQuién redacta las leyes? Los modelos de redacción «concentrada» y de redacción «difusa» de los proyectos de ley», en Revista de las Cortes Generales, núm. 21.

5 Criterio que después ha venido a confirmar el artículo 19 de la Ley Orgánica 3/2007, de 22 de marzo, para la igualdad efectiva de hombres y mujeres al exigir la elaboración de un Informe sobre impacto de género en relación con los proyectos de disposiciones de carácter general y planes de especial trascendencia económica, social, cultural o artística que haya de aprobar el Consejo de Ministros. 
de forma simultánea a la elaboración de éste ${ }^{6}$; y, en fin, que la Ley 40/2015, de 1 de octubre, de Régimen Jurídico del Sector Público da una nueva redacción a todo el Título V de la Ley del Gobierno ( «De la iniciativa legislativa y la potestad reglamentaria del Gobierno», artículos 22 a 28), afectando, pues, a la regulación del procedimiento de elaboración de los anteproyectos de ley, si bien esta modificación entrará en vigor a partir del 2 de octubre de $2016^{7}$.

B) La asunción, en su caso, del impulso autonómico por parte del Gobierno del Estado: el «pase previo» del Consejo de Ministros

Pasemos, pues, a la apreciación del marco normativo que rige la actuación del Gobierno central iniciada —en su caso — cuando éste recibe el impulso legislativo autonómico, con la idea clara de que esa apreciación debe ceñirse sobre todo a las especificidades que pueda introducir en dicho procedimiento el hecho de que el estímulo de tal iniciativa proceda de un Parlamento autonómico y no - como es lo normal - de los Departamentos del propio Gobierno. Aunque un mínimo de referencias a los aspectos generales del tema será inevitable, no tendría ningún sentido repetir aquí cuanto es de conocimiento común respecto del procedimiento legislativo en su dimensión más genérica. No obstante, no estará de más que advirtamos una seria dificultad en la tarea anunciada: el hecho de que la regulación del procedimiento de elaboración de los proyectos de ley en nuestro ordenamiento jurídico no define un proceso formal a cargo del Gobierno en sentido estricto y riguroso, por cuanto, de una parte, enumera una serie de trámites aislados (algunos de ellos no exentos de cierta complejidad) que considera requisitos mínimos para la aprobación de una norma, un conjunto de fases con eficacia desigual que no

${ }^{6}$ El 11 de diciembre de 2009, el Consejo de Ministros aprobó la «Guía Metodológica para la elaboración de la Memoria del Análisis de Impacto Normativo». Esta guía nace como una herramienta básica para los órganos o centros directivos que elaboran normas, ya que establece las pautas orientativas metodológicas y el orden de actuaciones que han de seguir a la hora de elaborar los diferentes elementos que componen la Memoria.

7 Tampoco habría que olvidar, sin que sea preciso dedicarle aquí un desarrollo más extenso, que habitualmente son los Decretos que regulan la estructura de cada Ministerio los que acaban de fijar, para cada sector de la vida pública, determinados aspectos de detalle que hacen a los procedimientos de elaboración interna de los correspondientes borradores de anteproyectos de Ley, lo que no tendrá ninguna relevancia cuando dicho texto ya le llegue redactado al Gobierno central, pero sí pasará a tenerla cuando la Asamblea de la Comunidad Autónoma lo que haga sea confiarle a éste la tarea de confeccionarlo. Especial importancia reviste, a este respecto, el Real Decreto 199/2012, de 23 de enero, por el que se desarrolla la estructura orgánica básica del Ministerio de la Presidencia y se modifica el Real Decreto 1887/2011, de 30 de diciembre, por el que se establece la estructura orgánica básica de los departamentos ministeriales. 
conforman un procedimiento completo, y, de otra parte, ese proceso está pensado por el Derecho más desde la perspectiva de las Cámaras que desde la del Gobierno, por importante que sea su intervención en el mismo ${ }^{8}$.

De acuerdo con lo dicho y según el artículo 22.2 LG, el procedimiento de elaboración de los proyectos de ley se iniciará en el Ministerio o Ministerios competentes mediante la elaboración del correspondiente anteproyecto 9 . No obstante, en el supuesto que aquí nos concierne, y pese a que esa sea la dicción literal del citado artículo 22.2 LG, semejante prescripción habrá que entenderla referida tan sólo al caso en el cual la Comunidad Autónoma inste al Gobierno a que sea él el que, a través de sus Departamentos y de sus servicios técnicos, elabore el proyecto en cuestión, ya que, de no ser así (esto es, si, en cambio, el parlamento autonómico ha materializado tal impulso en un anteproyecto ya articulado), estaremos en presencia de un típico supuesto de iniciativa legislativa gubernamental nacida de un estímulo normativo externo al propio Gobierno y ya formulada, respecto del cual, por tanto, no tiene ningún sentido dicha norma.

Lógicamente, habrá ya un anteproyecto o texto articulado y el Ministerio o Ministerios correspondientes no tendrán nada que decir sobre el mismo antes de que el Consejo de Ministros lo conozca y considere. Otra cosa distinta es que, cuando llegue este momento, el Gobierno tenga todo el derecho del mundo a examinar si el texto remitido por la Comunidad Autónoma es compatible o no con su programa normativo, de donde (aunque lo normal será que, si esa compatibilidad no existe, el Gobierno lo rechace sin más) nada impide que opte por aceptarlo y reenviarlo al Ministerio o Ministerios del ramo para que hagan en él las modificaciones oportunas antes de seguir su tramitación. Sólo en tan atípico supuesto (amén, claro está, del referido al impulso no articulado) lo dicho por el artículo 22.2 LG podría ser aquí la norma a tener en cuenta.

${ }^{8}$ Vid., al respecto, SANZ PÉrez, A.L. (2015): «La importancia del procedimiento preparlamentario de elaboración de un proyecto de ley o las preguntas sin respuesta», en Revista Aranzadi Doctrinal, núm. 4, pp. 125-132.

9 Artículo 22.2 LG (vigente hasta el 1 de octubre de 2016): «El procedimiento de elaboración de proyectos de ley a que se refiere el apartado anterior, se iniciará en el ministerio o ministerios competentes mediante la elaboración del correspondiente anteproyecto, que irá acompañado por la memoria, los estudios o informes sobre la necesidad y oportunidad del mismo, un informe sobre el impacto por razón de género de las medidas que se establecen en el mismo, así como por una memoria económica que contenga la estimación del coste a que dará lugar. En todo caso, los anteproyectos de ley habrán de ser informados por la Secretaría General Técnica». A partir del 2 de octubre de 2016 entrará en vigor la nueva redacción que la Ley 40/2015, de 1 de octubre, de Régimen Jurídico del Sector Público, da al artículo 22 LG: «El Gobierno ejercerá la iniciativa y la potestad reglamentaria de conformidad con los principios y reglas establecidos en el Título VI de la Ley 39/2015, de 1 de octubre, del Procedimiento Administrativo Común de las Administraciones Públicas y en el presente Título». 
A resultas de lo dicho, queda claro que, como primer trámite a seguir por una propuesta de ley remitida por una Asamblea autonómica, el Gobierno debería examinarla y decidir expresamente sobre ella, bien aceptándola o rechazándola si ya le vino redactada, bien dando traslado de tal estímulo al Ministerio o Ministerios competentes para que elaboren el correspondiente anteproyecto en caso contrario, y ello — como es lógico- en razón de la libertad de que goza este órgano en el ejercicio de su potestad de iniciativa.

En concreto, esta decisión política ha de corresponder formalmente al Consejo de Ministros mediante Acuerdo ${ }^{10}$, que habrá de notificarse a la Asamblea autonómica proponente y que puede considerarse el auténtico «pase previo» del proyecto autonómico a su posterior elaboración gubernamental y, en su caso, parlamentaria ${ }^{11}$. Por lo demás, la referencia que acabamos de hacer a la libertad de la que goza el Gobierno a la hora de aceptar o rechazar el estímulo legislativo que le llega de una Comunidad Autónoma viene a certificar que nos encontramos ante un verdadero «acto político» $y$, como tal, excluido del control de la jurisdicción contencioso-administrativa y aun del recurso de amparo, bien que ello tan sólo en los términos en los que así lo tiene declarado el Tribunal Constitucional en su sentencia 63/1983, de 20 de julio.

Los momentos en los que debería articularse la adopción de este «pase previo», esto es, de este Acuerdo de aceptación o de rechazo de la iniciativa autonómica por parte del Consejo de Ministros, son de sobra conocidos. Constituyen ese material del que decíamos antes que pertenece a la teoría general de la actuación del Gobierno en su condición de iniciador de la ley y que, por lo tanto, no tiene ningún sentido que lo reproduzcamos aquí con mayor extensión. En síntesis — reducimos, pues, a ello nuestro recuerdo—, esos pasos son los siguientes:

a) Recibido por el Gobierno el proyecto autonómico de ley estatal, aquél debe pasarlo a la Comisión General de Secretarios de Estado y Subsecretarios para que ésta, como órgano encargado de la preparación de los Consejos de Ministros, en su reunión semanal, realice tal labor respecto del proyecto autonómico men-

${ }^{10}$ Conforme al artículo 25 d) LG, las decisiones del Consejo de Ministros que no deban adoptar la forma de Real Decreto revisten la forma de Acuerdos.

${ }^{11}$ La exigencia de este "pase previo» cristaliza por primera vez en las «Instrucciones para la tramitación de asuntos en los órganos colegiados del Gobierno (texto refundido)» de 1989 antes referidas, las cuales establecían que hasta que el Consejo de Ministros no se pronunciara favorablemente sobre la idea o cuestión presentada no se pasaba a la fase ulterior de redacción de borradores por el centro directivo o los expertos externos, y se articulaba mediante la inclusión de la cuestión en el orden del día del Consejo. 
cionado $^{12}$; esa labor deberá incluir su informe sobre la pertinencia o impertinencia de dicho proyecto y la recomendación que en su caso proceda; normalmente, el tema no debería ir a parar al «índice verde», donde se recogen los asuntos prácticamente resueltos por los Subsecretarios, sino al «índice rojo», donde van a parar las cuestiones que el Consejo de Ministros debe examinar con más cuidado, a fin de que éste pueda conocerlo con la atención que merece un asunto ubicado en el importante marco de las relaciones interterritoriales, pero sobre este punto es muy difícil dogmatizar en sede teórica.

b) Llegada la fecha del Consejo de Ministros e incluido el tema en el orden del día ${ }^{13}$, el Gobierno deberá resolver si hace suyo o no el proyecto que le ha hecho llegar la Comunidad Autónoma. Para hacerlo deberá cerciorarse antes (puesto que la Comisión General de Secretarios de Estado y Subsecretarios habrá tenido, en principio, que ocuparse de ello) de que el proyecto le llega en las condiciones que impone el artículo $88 \mathrm{CE}$ («acompañado de una exposición de motivos y de los antecedentes necesarios para pronunciarse sobre él») y con los Informes - memoria económica, impacto de género, Consejo de Estado, Consejo de Política Fiscal y Financiera..., en los supuestos en los que ello proceda- que el ordenamiento jurídico hace, en su caso, obligatorios.

c) Si la iniciativa incluye un texto articulado, a la decisión del Gobierno, positiva o negativa, no tiene por qué seguirle trámite alguno (salvo la remisión al Congreso, si es positiva), ya que el Derecho no tiene prevista su existencia ${ }^{14}$.

12 Artículo 8.4 LG: «Todos los asuntos que vayan a someterse a aprobación del Consejo de Ministros deben ser examinados por la Comisión, excepto aquéllos que se determinen por las normas de funcionamiento de aquél». No obstante, a partir del 2 de octubre de 2016 podría prescindirse excepcionalmente de este trámite y someterse directamente la propuesta autonómica al Consejo de Ministros si se considerara que la misma reviste carácter de urgencia, y ello al amparo de la nueva redacción que la Ley 40/2015, de 1 de octubre, de Régimen Jurídico del Sector Público da al artículo 8.5 a) LG: «Corresponde a la Comisión General de Secretarios de Estado y Subsecretarios:... a) El examen de todos los asuntos que vayan a someterse a aprobación del Consejo de Ministros, excepto ....aquéllos que, excepcionalmente y por razones de urgencia, deban ser sometidos directamente al Consejo de Ministros», decisión ésta que corresponde tomar al Presidente del Gobierno, lo que no es sino una más de las manifestaciones — en este caso ad intradel primado del Presidente sobre el resto de los miembros del Gobierno, es decir, del primado presidencial en la acción de gobierno que consagra nuestro ordenamiento jurídico.

${ }^{13}$ Inclusión que corresponde decidir al Presidente del Gobierno en virtud del artículo 2.2.g) LG: «Corresponde al Presidente del Gobierno... convocar, presidir y fijar el orden del día de las reuniones del Consejo de Ministros, sin perjuicio de lo previsto en el artículo 62.g) de la Constitución».

14 Ahora bien, a partir del 2 de octubre de 2016 entrará en vigor la nueva redacción que la Ley 40/2015, de 1 de octubre, de Régimen Jurídico del Sector Público da al artículo 26.5.párrafo $4 .^{\circ} \mathrm{LG}$, según la cual «en todo caso, los anteproyectos de ley... deberán ser informados por la Secretaría General Técnica del Ministerio o Ministerios proponentes». Por consiguiente, creemos que a partir de esa fecha el texto articulado enviado por una Asamblea autonómica debería ser 
Distinto es que debiera hacerlo. En cambio, si la acepta y no incorpora dicho texto, y la decisión es positiva, el Gobierno tendrá que resolver cuál es el camino que vaya a seguir para que sus servicios se hagan cargo de la elaboración del anteproyecto correspondiente. Lo normal será que lo que haga — puesto que éste es el camino común y dado que así lo impone el artículo 22.2 LG — sea trasladar dicho encargo al Ministerio o Ministerios a los que el asunto corresponda por razón de la materia, cuyos servicios técnicos procederán a esa elaboración en los términos que ya conocemos. Desde aquí — ahora ya sí como proyecto articulado- el texto volverá al Consejo de Ministros que tomará la decisión definitiva ${ }^{15}$.

informado por la Secretaría General Técnica del Ministerio o Ministerios competentes por razón de la materia.

${ }^{15}$ La Ley 40/2015, de 1 de octubre, de Régimen Jurídico del Sector Público ha dado también una nueva redacción al artículo 26 LG, donde se regula el procedimiento que, para la redacción de los anteproyectos de ley, será de aplicación a partir del 2 de octubre del presente año, y en el que destaca la previsión de un trámite de consulta pública. Podemos resumir tal procedimiento así: a) La redacción de un anteproyecto de ley estará precedida de cuantos estudios y consultas se estimen convenientes para garantizar el acierto y la legalidad de la norma (entendemos que tales consultas, en el caso que nos ocupa, podrían plantearse también a la Asamblea autonómica proponente si se considera necesario). b) Se sustanciará un trámite de consulta pública, a través del portal web del departamento competente, con carácter previo a la elaboración del texto, en la que se recabará opinión de los sujetos potencialmente afectados por la futura norma y de las organizaciones más representativas acerca de los extremos relacionados en el artículo; consulta pública — de la que podrá prescindirse si se cumplen los requisitos descritos en el párrafo 2. ${ }^{a}$ del punto 2 del artículo- que deberá realizarse de tal forma que todos los potenciales destinatarios de la norma tengan la posibilidad de emitir su opinión, para lo cual deberá proporcionarse un tiempo suficiente, que en ningún caso será inferior a quince días naturales. c) El centro directivo competente elaborará con carácter preceptivo una «Memoria del Análisis de Impacto Normativo», que deberá contener los extremos previstos en el artículo, entre los que se encuentra «un resumen de las principales aportaciones recibidas en el trámite de consulta pública». d) Cuando la norma pudiera afectar a la distribución de competencias entre el Estado y las Comunidades Autónomas —algo bastante habitual en la iniciativa legislativa autonómica-, será necesario informe previo del Ministerio de Hacienda y Administraciones Públicas. e) Y Si la norma afecta a los derechos e intereses legítimos de las personas, el centro directivo competente pondrá en marcha un trámite de audiencia e información públicas por un plazo mínimo de 15 días, que podrá ser reducido hasta un mínimo de siete días hábiles cuando razones debidamente motivadas así lo justifiquen, así como cuando se aplique la tramitación urgente de iniciativas normativas. Este trámite de audiencia e información públicas sólo podrá omitirse cuando existan graves razones de interés público (que deberán justificarse en la Memoria del Análisis de Impacto Normativo). f) Se recabará el dictamen del Consejo de Estado u órgano consultivo equivalente cuando fuera preceptivo o se considere conveniente. g) En fin, cumplidos los trámites anteriores, la propuesta se someterá a la Comisión General de Secretarios de Estado y Subsecretarios y se elevará al Consejo de Ministros para su aprobación y su remisión al Congreso de los Diputados, acompañándolo de una Exposición de Motivos y de la 
d) Una vez aprobado el proyecto por el Consejo de Ministros, y hecho suyo por tanto por el Gobierno, el texto será remitido como tal proyecto de ley a la Mesa del Congreso para iniciar allí su tramitación parlamentaria.

Estos son, en fin, los pasos que seguirá el proyecto en su fase gubernativa cuya descripción dejamos con ello agotada. El problema es que el Gobierno habitualmente se desentiende de tal estímulo y, por lo tanto, este iter rara vez o nunca llega a producirse. Pero esa es otra cuestión que nos desplaza ya al terreno de lo que el Derecho no dice, esto es, al terreno de los hechos en cuya exposición entraremos después. Por ahora, permítasenos concluir este epígrafe, en el que consta toda la información relativa al régimen normado de esta figura, con un excursus sobre la cara y la cruz que presenta esta apelación a la iniciativa del Gobierno como mecanismo mediador presuntamente utilizable a favor de los intereses de las Comunidades Autónomas.

C) Excursus: Ventajas e inconvenientes que puede comportar esta modalidad de iniciativa autonómica. Consideraciones sobre la supuesta preeminencia de la iniciativa legislativa del Gobierno

Una vez cumplido el recorrido anterior y conocidos los aspectos procesales de la vía que estamos analizando, se nos hace cierto que ese itinerario abre preguntas sobre la razón de ser de esta figura, lo que no está muy lejos de significar que las abre sobre sus ventajas e inconvenientes. ¿Tiene realmente sentido habilitar esta segunda vía para que por ella circule dicha iniciativa cuando las Comunidades Autónomas ya tienen franco, si quieren, el camino directo al Congreso de los Diputados, primera Cámara de nuestro Parlamento y verdadero legislador? Pues la respuesta a esta cuestión habrá que construirla sobre ese cálculo de costes y beneficios, de ventajas e inconvenientes, que mencionábamos hace un momento.

Si para abordar ese análisis nos desplazamos a lo ya dicho por la doctrina, nos encontraremos con que, para un amplio sector de la misma, esta ampliación a dos vías y, en consecuencia, la posibilidad de que la segunda de ellas permita recurrir a la iniciativa del Gobierno para alcanzar el resultado normativo que la Comunidad Autónoma pretende lograr, tiene su razón de ser - y por lo tanto su ventaja — en que por este camino la Comunidad de que se trate puede beneficiarse de los muchos privilegios y prerrogativas con los que cuenta, a la hora de su tramitación, la iniciativa legislativa gubernamental — dígase, los proyectos de ley- y que, sin embargo, no existen a favor de las demás formas de iniciativa — léase, las proposi-

documentación propia del procedimiento de elaboración a que se refieren las letras b) y d) del artículo 7 de la Ley 19/2013, de 9 de diciembre, de transparencia. 
ciones de ley—ahí incluidas las que las Comunidades Autónomas puedan remitir al Congreso de los Diputados al amparo del artículo 87.2 CE.

Con toda claridad lo afirma así Gerpe Landín cuando dice que la doble opción que mencionamos es «...un aspecto elogioso desde la perspectiva de las Comunidades porque ello posibilita que la iniciativa autonómica se acoja a los beneficios procedimentales de que goza la iniciativa de origen gubernamental» ${ }^{16}$. Y no otra cosa opinan quienes exponen — bien que desde una perspectiva más general - los muchos argumentos que abonan la primacía del Gobierno en la iniciativa legislativa ${ }^{17}$. A la postre, se trata de fortalecer la posición del Ejecutivo en la elaboración de la ley frente a posibles entorpecimientos del iter legis que a nadie, y a ese Ejecutivo el primero, deberían convenir. Es lo que Garrorena Morales ha intentado compendiar cuando formula los principios de «agilidad procesal» $\mathrm{y}$ «de prioridad procesal» debida a los proyectos de ley como un modo de dotar con eficacia al Gobierno del derecho que necesita ${ }^{18}$. Estamos, en fin, ante una ventaja que ahora las Comunidades Autónomas podrían utilizar a su favor con sólo preferir el camino de la estimulación de la iniciativa legislativa del Gobierno a la hora de encauzar su propuesta de ley del Estado.

Ahora bien, aceptado el planteamiento anterior en la parte de verdad que indudablemente posee (el proyecto de la Comunidad se beneficiaría así de las ventajas que corresponden a la primacía o prioridad del Gobierno en la elabora-

16 Gerpe Landín, M. (1980): «Relaciones entre las Cortes Generales y las Asambleas de las Comunidades Autónomas. La iniciativa legislativa de las Comunidades Autónomas en la Constitución española de 1978», en M. A. Aparicio (coord.), Parlamento y sociedad civil, Barcelona, Universidad de Barcelona, p. 167.

${ }^{17}$ Sobre la prioridad de los proyectos de ley, vid., entro otros, LuCas Verdú, P. (1977): «Iniciativa legislativa», en Nueva enciclopedia jurídica, Barcelona, Seix, vol. XII, pp. 623-627; ОтTO Y PARDO, I. (1980): «La posición constitucional del Gobierno», en Documentación Administrativa, núm. 188, p. 178; Herrero Lera, M. (1985): «Artículo 87: Iniciativa legislativa», en O. Alzaga Villaamil (director), Comentarios a la Constitución española de 1978, Madrid, Cortes GeneralesEdersa, pp. 209-240; Dorrego de Carlos, A. (1988): «Artículo 88: Iniciativa legislativa gubernamental», en O. Alzaga Villaamil (director), Comentarios a la Constitución española de 1978, Madrid, Cortes Generales-Edersa, pp. 289-353; Cascajo Castro, J. L. (1992): «La forma parlamentaria de Gobierno en el sistema constitucional español, en Revista Vasca de Administración Pública, núm. 34, pp. 13 y ss.; Pérez Francesch, J. L. (1996): El Gobierno, Madrid, Tecnos, pp. 29-30; García-Escudero Márquez, P. (1999): «La prioridad en la tramitación parlamentaria de los proyectos de ley», en Teoría y realidad constitucional, núm. 3, pp. 125-164; GarcíaEscudero Márquez, P. (2000): La iniciativa del Gobierno, Madrid, Centro de Estudios Políticos y Constitucionales, 2000; GARRIDO MAYOL, V. (2010): Las garantías del procedimiento prelegislativo: la elaboración y aprobación de los proyectos de ley, Valencia, Tirant lo Blanch, pp. 34-44.

18 Garrorena Morales, A. (1980): El lugar de la ley en la Constitución española, Madrid, Centro de Estudios Constitucionales, pp. 114-115. 
ción de la ley), entendemos que la cuestión debe ser analizada con mayor cuidado, tratando de ver si esas ventajas lo son de una manera tan neta como se afirma y si, al lado de ellas, no existen inconvenientes que también deban ser puestos en la balanza. Proceder de esa manera va a requerir que encaremos el tema en una triple dimensión. En primer lugar, va a ser necesario que veamos más a fondo en qué consiste, esto es, por qué existe y para qué existe esa aludida prevalencia o primacía del Gobierno que aquí acaba por convertirse en tan crucial. Tras ello, será preciso que digamos con mayor puntualidad cuáles son las facultades o ventajas en las que se concreta esa prerrogativa privilegiada del Gobierno, porque únicamente así sabremos de lo que hablamos. Y en tercer lugar, ya con toda proximidad al tema que nos concierne, habrá que ver si dichas ventajas —que sin duda lo son para el Gobierno- lo son también, y en qué medida, para la Comunidad Autónoma impulsora del proyecto.

Por lo que hace a la razón de ser de la primacía de la que goza la iniciativa legislativa del Gobierno, y de la que, por tanto, podría beneficiarse la Comunidad Autónoma que la insta, hay que decir que esa razón está claramente conectada al tipo de régimen político o sistema de gobierno dentro del cual se produce, y difícilmente podría entenderse sin tal referencia. En efecto, en un sistema de separación rígida de poderes esa prevalencia de la iniciativa del Gobierno ni siquiera tiene razón de ser, tanto que, en este contexto, lo normal será que el Gobierno carezca incluso de tal capacidad de iniciar las leyes. Y es que, en realidad, no la necesita porque para evitar que la legislación, obra del Parlamento, entorpezca su acción como Ejecutivo le bastará con activar su facultad de impedir o vetar la ley.

Así lo vio Montesquieu, cuya visión de Inglaterra se produjo cuando el régimen inglés era todavía una Monarquía constitucional no parlamentarizada y donde, por tanto, se suponía que la Corona poseía la potestad de negarle su sanción a las leyes sin mayores dificultades: en la expresión que utiliza Montesquieu, no es necesario que el poder Ejecutivo proponga las leyes puesto que su «faculté d'empecher» le permite rechazar las que hubiera deseado que no existie$\operatorname{ran}^{19}$. Y así es también, con toda coherencia, desde 1787, en la Constitución de los Estados Unidos (donde el Presidente carece de competencia constitucional para iniciar la ley y sólo la débil mención que el artículo II, sección 3, hace a la posibilidad de «informar al Congreso sobre el estado de la Unión, encomendado a su consideración las medidas que estime necesarias y oportunas» ha permitido que, vía mensaje, aquél pueda tener una indirecta intervención en el impulso de las leyes) y en el capítulo III del Título III de la Constitución francesa de 1791, ambos

19 Montesquieu (1748): De l'esprit des lois, libro XI, cap. VI. 
regímenes basados en la separación rígida de los tres poderes del Estado. E incluso cabría decir que las cosas siguen siendo parcialmente iguales en los regímenes parlamentarios — ya de separación flexible_ cuando ese parlamentarismo es aún dualista o de dos confianzas (Cartas francesas de 1814 y de 1831, Estatuto Real de 1834, Constituciones españolas del siglo XIX...), puesto que en ellos, si bien la Corona comienza a tener la capacidad de iniciar las leyes, mantiene aún muy activa su facultad de actuar sobre éstas mediante el veto, esto es, mediante su capacidad de impedir.

Así las cosas, es en los regímenes parlamentarios de tipo monista o de una sola confianza, la del Parlamento, y mucho más desde la aparición del llamado parlamentarismo racionalizado, donde la figura de la prevalencia atribuible a la iniciativa legislativa del Gobierno cobra todo su sentido. Aquí se produce, como es bien sabido, una fuerte integración del Gobierno con la mayoría parlamentaria que resitúa a ambos actores en una posición peculiar a estos efectos. El Gobierno pasa a recibir en plenitud la función de dirección política, bien que para ejercerla debe contar con la confianza y colaboración del Parlamento, y éste - escuchadas sus necesidades en clave legislativa- debe de satisfacerlas, lo que convierte a la iniciativa legislativa gubernamental en un verdadero acto de «indirizzo político». Las posiciones se invierten, por tanto, y es el Gobierno el que, como dice Elia, acaba ocupando el lugar de un auténtico «comité directivo» del Parlamento o, lo que es igual, de la mayoría parlamentaria ${ }^{20}$.

La iniciativa legislativa del Gobierno, ejercida a través de la incesante presentación de proyectos de ley, es así la forma que aquél tiene de marcarle a las Cámaras las leyes que necesita y la orientación o dirección en la que las necesita. Y toda prevalencia concedida por el Derecho a tales proyectos de ley no es sino la manera que el mismo tiene de potenciar ese esencialísima función de dirección que al Ejecutivo le incumbe. Cuando nuestra Constitución dice en su artículo 97 que «el Gobierno dirige» la política interior y exterior del Estado, está asumiendo tal disposición de piezas, lo que autoriza a Punset Blanco a decir que: «...iniciativa legislativa y dirección política guardan entre sí una relación de medio a fin, por lo que la preeminencia gubernamental en este ámbito se corresponde con la necesidad de instrumentalizar la aplicación del artículo 97, que asigna al Gobierno la dirección política» ${ }^{21}$.

20 Elia, L. (1951): «Il governo come comitato direttivo del Parlamento», en Rivista Civitas, núm. 4, pp. 59 a 66.

21 Punset Blanco, R. (1982): «La iniciativa legislativa en el ordenamiento español», en Revista de Derecho Político, núm. 14, p. 78. 
Vista, pues, la cuestión de esta manera, cabría decir que hay un segundo título desde el cual es posible considerar positiva la utilización por las Comunidades Autónomas de la vía del Gobierno como forma de impulsar la ley estatal que estiman necesaria. No es ya que, a través de ella, las Comunidades Autónomas puedan beneficiarse de todas las prerrogativas y privilegios que conlleva la primacía de los proyectos de ley frente a las proposiciones. Es que, además, si acabamos de convenir que el Gobierno ejerce su función de dirección, orientación o indirizzo del proceso político — amén de por otros medios - a través de la presentación de aquellos proyectos de ley con los cuales intenta marcar el sentido de dicho proceso, habrá que aceptar también que las Comunidades tiene aquí un instrumento idóneo para influir en esa dirección reorientándola en el sentido de sus particulares intereses cuando crean que eso es lo que conviene a los mismos.

Pero el interrogante que aquí se nos cruza, conforme a lo que ya teníamos anunciado, consiste en saber de qué estamos hablando cuando nos referimos a la prevalencia, primacía o ventaja de los proyectos de ley nacidos del Gobierno, porque dependerá de cuál sea el contenido de esta prerrogativa privilegiada el que ese beneficio, que ahora pretendemos trasladar a las Comunidades Autónomas, les compense o no a la hora de preferir dicha vía. En síntesis, el elenco de tales ventajas, dejando para después el análisis de su conveniencia, y haciendo aquí omisión de algunas de ellas que apenas guardan relación con nuestro objeto (recordemos, por ejemplo, que la iniciativa legislativa del Gobierno se beneficia de una clara reserva material, pues sólo por esta vía se pueden iniciar determinadas leyes, artículos 131.2 y 134.1 CE; o que el Gobierno puede oponerse a la tramitación de aquellas proposiciones de ley y de aquellas enmiendas a un proyecto de ley que comporten aumento de gastos o impliquen disminución de ingresos, artículo 134.6 CE...) es el siguiente:

a) Desde una perspectiva todavía muy general, el Gobierno tiene, desde luego, el derecho de estar presente y participar, bien que lógicamente con voz pero sin voto, en las reuniones que celebre la Junta de Portavoces, facultad que aquél puede poner a contribución de sus proyectos y, en nuestro caso, de aquellos proyectos de ley estatal que las Comunidades Autónomas hubieran querido encomendar a su impulso (artículo 39.2 RC y artículo 43.2 RS).

b) Posee, además, el nada menor derecho de pedir que se incluya una cuestión en el orden del día de una sesión y de imponer, asimismo, que su debate y votación gocen de prioridad (derecho de prioridad) sobre los demás asuntos que la Cámara fuese a tramitar o estuviese tramitando. El artículo 67.3 RC dice que: «El Gobierno podrá pedir que en una sesión concreta se incluya un asunto con carácter prioritario, siempre que éste haya cumplido los trámites reglamentarios que le hagan estar en condiciones 
de ser incluido en el orden del día». Y el Reglamento del Senado, con especial referencia al derecho de prioridad, afirma rotundamente en su artículo 105 que: «Los proyectos del Gobierno recibirán tramitación prioritaria sobre las proposiciones de ley».

c) Amén de lo anterior, los miembros del Gobierno disponen del privilegio de poder intervenir en los debates parlamentarios — ahí incluido el debate de las leyes— haciendo «uso de la palabra siempre que lo soliciten» (artículo $70.5 \mathrm{RC}$ ), lo que les libera del riesgo de que los muy estrictos tiempos parlamentarios existentes a este respecto pueden atropellarlos o reducirlos al silencio. En igual sentido, el artículo 84.4 RS.

d) Ya en el particular terreno de la tramitación propia de los proyectos de ley, la iniciativa legislativa del Gobierno goza de la ventaja que supone el no necesitar cubrir el trámite de la toma en consideración, tan esencial, en cambio, para las proposiciones de ley (y, por tanto, para esta iniciativa si la Comunidad Autónoma correspondiente hubiera elegido remitirla como tal proposición al Congreso de los Diputados). En efecto, una vez realizada su admisión a trámite por la Mesa de la Cámara, los proyectos de ley quedan automáticamente aceptados (vid., in fine, lo que dice el artículo $109 \mathrm{RC}$ ) y, en consecuencia, no es necesario pasar a su toma en consideración sino que se puede entrar directamente, sin mayores exigencias ni requisitos, en su enmienda, debate y votación.

e) En fin, el Gobierno dispone de la facultad de pedir la convocatoria de las Cámaras en sesión extraordinaria (artículo 73.2 CE), así como del poder de declarar urgente la tramitación de un proyecto de ley, con efectos sobre los tiempos a cubrir en el Senado (artículo 90.3 CE), prerrogativas ambas que también podría utilizar respecto del objeto que nos ocupa.

Parecería, pues, que no son pocas, en principio, las ventajas que comporta el uso de esta vía. Y desde el punto de vista del Gobierno en su actividad cotidiana como promotor de las leyes, está claro que lo son. Sin embargo, la cuestión no es tan diáfana cuando de lo que se trata es de saber si lo son, asimismo, para las Comunidades Autónomas que quieran acogerse a esta fórmula a la hora de impulsar una iniciativa de la ley estatal pensando tal vez en beneficiarse de tales privilegios. Y aquí la respuesta tiene que ser ponderada teniendo en cuenta una triple perspectiva.

Desde el ángulo de cada una de esas ventajas, no está nada claro que lo sean de una manera tan decisiva como su mero enunciado parece sugerir. Muchos de tales privilegios son prerrogativas genéricas (presencia en Junta de Portavoces, derecho privilegiado al uso de la palabra en los debates, convocatoria de sesiones extraordinarias, declaración de urgencia...) que jugarían igual si la vía elegida hubiera sido la otra, la remisión como proposición de ley al Congreso de los 
Diputados — ninguna ventaja especial, por tanto- $y$, además, no añaden nada particularmente relevante a la tramitación normal de los proyectos de ley vista desde la perspectiva que aquí nos interesa.

Otras de esas ventajas (fundamentalmente, la eliminación del trámite de la toma en consideración) tienen una apariencia mucho más llamativa; sin embargo, García-Escudero Márquez ha podido poner un eficaz empeño en demostrarnos, con razón, que tampoco esta superioridad es cierta tan y, si se nos apura, en que ni siquiera es tal: «...permítaseme al menos preguntarme —escribe, con la cabeza puesta en la similitud de situaciones que se produce cuando, respecto de una proyecto de ley, se presenta una enmienda de totalidad con solicitud de devolución del proyecto al Gobierno- por qué la doctrina no presta la más mínima atención al trámite de debate de totalidad a que son sometidos tanto proyectos como proposiciones, y en concreto, a la posibilidad de devolución al Gobierno de los primeros por el Congreso. ¿No cabe establecer un cierto paralelismo entre la toma en consideración de las proposiciones de ley y la posibilidad de devolución de los proyectos de ley al Gobierno?». En su criterio, ese paralelismo existe y le permite afirmar que, salvados algunos extremos de menor cuantía, entre ambas situaciones se da una verdadera «identidad de naturaleza» ${ }^{22}$.

La segunda perspectiva desde la que habría que analizar el tema de las ventajas e inconvenientes de esta vía nos desplaza a otra cuestión que aquí deviene crucial: la de la fluidez o no fluidez de las relaciones que existan entre la Comunidad Autónoma impulsora de la iniciativa legislativa de la que venimos hablando y la mayoría política dominante en las Cortes Generales, en este caso, en el Congreso de los Diputados. Y de este segundo cotejo vuelve a deducirse que los presuntos beneficios derivados de la utilización de la vía gubernamental por las Comunidades Autónomas no lo son en tan clara medida. Y no lo son porque si esas relaciones son fluidas y buenas (como sucederá cuando tanto la mayoría existente en el Parlamento central como la dominante en la Comunidad de que se trate pertenezcan a un mismo color político) la Comunidad Autónoma podrá obtener del Congreso, sin tener que recurrir a la mediación del Gobierno vía proyecto de ley para poder disponer de ellas, toda esa lista de ventajas que vimos que la iniciativa gubernamental acarrea. Y si, en cambio, esas buenas relaciones no existen (la Comunidad es de un color y el Gobierno y el Parlamento central de otro) lo normal es que ni proyecto de ley vía Gobierno ni proposición de ley vía Congreso de los Diputados vayan a prosperar; con abrirle la puerta del Gobierno a dicha iniciativa, no le hemos abierto puerta alguna.

22 García-Escudero Márquez, P. (2000): «La iniciativa legislativa en la Constitución española de 1978», en Revista Española de Derecho Constitucional, núm. 59, p.75. 
Y aún existe — decíamos - una tercera perspectiva desde la que procede abordar este asunto. Es la de los hechos. Una perspectiva a cuyo través se podrá comprobar que, debido a su mal diseño, esta figura o no funciona o funciona de una manera distorsionada, lo cual es, con toda seguridad, la mayor censura que puede hacerse de la misma. A ella le dedicamos el siguiente epígrafe.

\section{LO QUE EL DERECHO NO DICE. LOS HECHOS COMO «PASIVO» DE ESTA FIGURA}

\subsection{Una causa que todavía pertenece al terreno del Derecho: sobre el despropósito que supone el que a una facultad atribuida por la Constitución a los parlamentos autonómicos no le siga procedimiento o consecuencia alguna}

Parecería, a la vista de lo anterior, que — pese a existir- no son tantas ni tan ciertas las ventajas que acompañan al uso de esta vía, el estímulo de la iniciativa legislativa del Gobierno de la Nación, a la hora de activar las posibilidades que el artículo 87.2 CE ofrece a las Comunidades Autónomas. Para empezar, el capítulo de los inconvenientes no está todavía completo porque hasta ahora no hemos hecho ninguna mención (o sólo la hemos hecho de una manera menor y sobrevolada) a lo que sucede en el terreno de los hechos, cuando es precisamente en ellos donde el "pasivo» de esta figura se hace más evidente. Pero es que antes de llegar ahí todavía tenemos que seguir moviéndonos en el marco del Derecho, puesto que a él pertenece la causa principal que motiva los hechos a los que habremos de referirnos en el epígrafe siguiente. Esa causa no es otra, como el lector ya habrá advertido, que la ausencia de un efectivo procedimiento capaz de quedar anudado al ejercicio de su capacidad de estímulo por parte de la Comunidad Autónoma, un procedimiento que prolongue, en suma, la actuación de ésta con algún tipo de actuación necesaria a cargo del Gobierno de la Nación.

No se trata, en absoluto, de establecer un procedimiento tan preciso y pautado como el que sigue a dicha iniciativa cuando la Comunidad la ejerce ante el Congreso de los Diputados, ni tampoco de esperar que el Gobierno central adquiera obligaciones que excedan de su derecho a no hacerse cargo de ninguna iniciativa que no se avenga con su programa legislativo y de gobierno. Pero padeceríamos un espejismo considerable si creyéramos que todas las actuaciones referidas al Gobierno que arriba se describen y que sí pertenecen al mundo del Derecho (desde la recepción del estímulo por parte de tal Ejecutivo hasta su «pase previo» en Consejo de Ministros, llegando a la posibilidad de que éste active a sus departamentos y a sus servicios técnicos) constituyen ese procedi- 
miento que aquí se echa de menos. Obviamente, eso sí, si el Gobierno quiere hacerse cargo de dicho estímulo - lo dijimos en su lugar- éste es el procedimiento que, según dice el Derecho, habrá que seguir, pero lo que el Derecho no dice es que el Gobierno de la Nación lo tenga que seguir, y ni siquiera que tenga que darse por enterado o que acusar recibo de ello.

En estas condiciones, lo más exacto es mantener que tal procedimiento no existe o, al menos, que no existe — que es lo que aquí nos interesa-como obligación del Gobierno. Éste puede, por tanto, desentenderse de la cuestión, y mientras el Derecho no le conmine a obrar de otra manera esto es lo que hará. En puros términos técnicos, este planteamiento es, además, un claro despropósito. Cuando los juristas hablamos de los derechos y libertades solemos decir que no hay verdadero derecho allá donde a su declaración no le sigue una efectiva garantía. Pues aquí las cosas no son muy distintas. Establecer una concreta facultad a favor de un sujeto cualquiera (en este caso, a favor de los parlamentos de las Comunidades Autónomas, a los que la Constitución española habilita para activar la iniciativa legislativa del Gobierno central) y, sin embargo, no vincular después ninguna consecuencia o actuación necesaria a cargo del sujeto respecto del cual ha actuado, equivale a construir esa facultad como un vacío ayuno de toda entidad jurídica. En toda relación jurídica bilateral no hay facultad donde la otra parte no adquiere ningún correlativo deber, lo cual constituye la mejor descripción de la situación en la que nos encontramos.

\subsection{Y dos consecuencias de tal despropósito}

Para medir la trascendencia que tenga realmente esta ausencia de procedimiento al que el Gobierno de la Nación deba de atenerse, lo mejor será que traslademos el análisis al terreno de los hechos. Allí es donde podremos comprobar cómo ese vacío no es inocuo. Por lo menos dos consecuencias sí le son referibles. Una en el ámbito de la actuación que cabe esperar del Gobierno y otra en el contexto de la identidad misma de esta figura la cual va a padecer bastante a resultas de tan censurable déficit de buena técnica legislativa.

A) Una secuela imposible de evitar: el desentendimiento prácticamente total del Gobierno de la Nación

La primera de las consecuencias que cabe atribuir a esa ausencia de un procedimiento ineludible llamado a constreñir al Gobierno de la Nación a prolongar el estímulo autonómico con algún tipo de actuación a la que no se pudiera sustraer es —acabamos de adelantarlo_ que el Gobierno apenas se considera alu- 
dido por tal estímulo. En su implícita percepción de las cosas, el no tener la obligación de hacer nada de iure se confunde para él con el no tener que hacer nada de facto, con lo cual no cree estar en el deber no ya de debatir sino ni siquiera de atender dicha iniciativa. Eso es, al menos, lo que viene sucediendo en la casi totalidad de las situaciones. Comprobarlo de una manera más precisa, con una referencia casi estadística a los hechos, requeriría respaldar lo que se dice con una indagación puntual que aquí hemos intentado pero que la propia conformación viciada de esta figura a la hora de su práctica hace imposible. No hay datos porque los propios organismos que deberían tenerlos y facilitarlos no los poseen. Los hemos recabado de las distintas dependencias del Gobierno (Gabinetes de Presidencia, organismos encargados de las relaciones con las Comunidades Autónomas y con sus parlamentos...) y sus respuestas han sido elusivas cuando no frustrantes. No existe un registro cabal —más allá de los registros generales, que son otra cosa- donde el Gobierno tenga recogida la relación de los escritos en los que las Comunidades Autónomas hayan intentado estimular su iniciativa legislativa con la sugerencia de un objeto o, más aún, con el envío de un proyecto articulado de ley. Y, como no existe tal registro, tampoco existe constancia de en qué casos — hasta donde los haya habido y si los ha habido — ese estímulo ha tenido un tratamiento posterior o en qué ha consistido dicho tratamiento.

De los contactos informales con los que hemos tenido que suplir esa falta de información se deduce que la práctica más habitual y casi única por parte del Gobierno ha consistido en dejar pasar tales documentos sin activar ningún mecanismo de atención o, menos aún, de respuesta. Es verdad que muchas de las iniciativas legislativas que las Comunidades Autónomas le han hecho llegar han versado sobre objetos (inmigración, uniones de hecho, conflicto hidrológico, horarios comerciales...) sobre los que el Estado ha terminado adoptando una ley. Pero no cabe deducir de aquí que aquella iniciativa autonómica haya sido en la mayoría de los casos - y casi nunca - el origen de la ley mencionada. Habitualmente, esa ley ya estaba en el programa legislativo del Gobierno, y la Comunidad lo único que ha hecho ha sido reforzar o estimular el interés del Gobierno por su adopción. El otro canal por el que hemos intentado obtener noticias sobre el funcionamiento práctico de este instituto han sido los servicios técnicos de los parlamentos autonómicos. Pero tampoco aquí hemos tenido mejor fortuna porque, como es fácil de entender, ellos suelen hacer un seguimiento puntual del proceso - y eso no todos ni siempre — hasta donde el mismo atañe a su actividad (iniciativa, debate, aprobación y remisión al Gobierno central), pero no a partir de aquí, es decir, no a partir del momento en que dicha actividad comienza a corresponder al Gobierno de la Nación, que es lo aquí interesado. Tal vez deberían hacerlo, pero de nuevo los contactos informales mantenidos con tales servi- 
cios nos sitúan en un escenario conocido: por lo común, el seguimiento de esa parte del proceso no se hace porque el Gobierno central no suele contestar y ni siquiera acusar recibo de la recepción. No hay, por tanto, nada que seguir. Más aún, ese seguimiento no se produce — insisten algunas respuestas — porque la Comunidad no espera que el Gobierno conteste.

B) Y una práctica disfuncional ya comprobada: la utilización desviada de esta figura con propósitos distintos de los que se le suponen

En el terreno de sus efectos más negativos, una segunda consecuencia cabe conectar también al hecho de que el legislador no haya establecido ningún procedimiento necesariamente vinculado a la recepción por el Gobierno central del estímulo legislativo que la Comunidad le remite, un procedimiento a cuyos mínimos el Ejecutivo del Estado no pudiera sustraerse y cuya intención fuera, además, aproximar esta figura a su efectividad como técnica para el impulso —en positivo- del Gobierno de la Nación: puesto que aquí ese procedimiento no existe ni, por tanto, puede tener ni tiene marcada su finalidad, ello conduce a que en su práctica, dentro de dicho vacío, se cuelen — de hecho- finalidades distintas y aun contrarias a las que se supone que deberían estar en su lógica matriz. De hecho, en demasiadas ocasiones, en vez de perseguir con su uso el estímulo de la actuación del Gobierno, la Comunidad Autónoma parte del presupuesto de que — dado lo que pide y a quién se lo pide_ esa actividad del Gobierno central nunca se va a producir, con lo cual es obvio que dicha práctica, lejos de situarse en el terreno de la colaboración entre instituciones, termina pasando a jugar en el ámbito de los mecanismos de oposición, en este caso de los mecanismos de oposición entre la mayoría parlamentaria de la Comunidad Autónoma y sus fuerzas opositoras dentro de la Asamblea legislativa autonómica, a las que aquella mayoría consigue encarar, así, con ese reto difícil de asumir por éstas que es el tener que aceptar que es el Gobierno central de su propio color (distinto en este caso del color del Gobierno autonómico) el que permanece inerte y desentendido respecto del objeto cuya activación se le solicita.

En pocas palabras, por esta vía el estímulo de la iniciativa del Gobierno de la Nación deja de ser tal estímulo y se trasmuta en un hábil método para reconvertir los argumentos de la oposición contra la mayoría autonómica en argumentos de dicha oposición contra ella misma. La cuestión es muy compleja e incluye matices que sólo es posible apreciar sobre la realidad. Analizarla, no obstante, respecto de la práctica de las diecisiete Comunidades Autónomas tan sólo añadiría un exceso de complicación que la haría menos informativa y más difícil de abarcar. De ahí que nos haya parecido preferible acogernos a una técnica tan 
común para el trabajo jurídico como es la técnica del caso y que, en consecuencia, hayamos optado por seleccionar un caso tipo — en esta oportunidad, el caso de la Comunidad Autónoma de Murcia por las razones que expresamos en nota ${ }^{23}$ $\mathrm{y}$, sobre él, intentemos (con el sentido unitario y la coherencia interna que tal simplificación aseguran) aclarar cuantas cuestiones deja abiertas el planteamiento anterior. Viniendo, pues, a ello, los datos de la experiencia murciana son los siguientes.

Desde los inicios de su funcionamiento hasta el día de hoy, la Asamblea Regional de Murcia ha aprobado catorce solicitudes de iniciativa legislativa dirigidas al Gobierno de la Nación en materia de ley estatal ${ }^{24}$. Cinco de ellas las

${ }^{23}$ La selección de la Comunidad Autónoma de la Región de Murcia se hace (amén de porque la proximidad «física» de ese caso con el lugar universitario donde esta investigación se realiza posibilita un conocimiento más directo y exacto de dicha realidad) porque la práctica de tal Comunidad es muy variada y cubre bien, por ello, los distintos supuestos que debemos esclarecer.

${ }^{24}$ La relación de las catorce «solicitudes de iniciativa legislativa del Gobierno de la Nación» aprobadas que se mencionan en el texto es la siguiente:

A) Sin adjuntar texto:

- Solicitud de iniciativa legislativa del Gobierno de la Nación sin adjuntar texto, sobre medidas de apoyo a los trabajadores agrícolas de la Región. Aprobada como moción (BOAR núm. 120, de 08-05-89).

- Solicitud de iniciativa legislativa del Gobierno de la Nación sin adjuntar texto sobre elaboración de una ley estatal para la regulación de los horarios comerciales. Aprobada como moción (BOAR núm. 93, de 31-12-92).

- Solicitud de iniciativa legislativa del Gobierno de la Nación sin adjuntar texto sobre elaboración de un proyecto de ley estatal de protección a la familia. Aprobada como moción (BOAR núm. 164, de 05-05-94).

- Solicitud de iniciativa legislativa del Gobierno de la Nación sin adjuntar texto sobre necesidad de regular a través de una ley de convivencia las uniones de hecho. Aprobada como moción (BOAR núm.167, de 25-05-94).

- Solicitud de iniciativa legislativa del Gobierno de la Nación sin adjuntar texto sobre elaboración y aprobación del Plan Hidrológico Nacional. Aprobada como moción con modificaciones (BOAR núm.214, de 15-03-95).

- Solicitud de proyecto de ley sin adjuntar texto sobre elaboración del proyecto de ley de promoción de la autonomía personal y atención a las personas en situación de dependencia y propuestas de regulación. Aprobada como moción (BOAR núm. 99, de 22-03-2006).

- Estímulo de la iniciativa legislativa del Gobierno de la Nación sin adjuntar texto sobre modificación de la normativa reguladora del Impuesto sobre la Renta de las Personas Físicas. (BOAR núm. 122, de 14-10-10).

- Estímulo de la iniciativa legislativa del Gobierno de la Nación sin adjuntar texto sobre protección social a los autónomos desempleados que hayan agotado sus prestaciones por desempleo. (BOAR núm. 122, de 14-10-10).

- Estímulo de la iniciativa legislativa del Gobierno de la Nación sin adjuntar texto sobre regulación para homologación directa del título de Ingeniero Técnico al grado de Ingeniería (BOAR núm. 28, de 25-04-12). 
ha adoptado entre 1989 y 1995 . Entre marzo de 1995 y marzo de 2006, extenso periodo de casi once años que incluye las legislaturas sexta y séptima de las Cortes Generales, no aprobó, en cambio, ninguna iniciativa de este tipo. Y las otras nueve solicitudes al Gobierno se sitúan en el tiempo que va de marzo de 2006 a la actualidad ${ }^{25}$. Vista dicha práctica desde otra perspectiva, sólo en cuatro ocasiones (2010, trasvase Tajo-Segura; 2011, financiación autonómica; 2013, de nuevo financiación autonómica; 2013, relaciones paternofiliales) esa solicitud se ha hecho mediante la presentación de un texto articulado debidamente enmendado y discutido por la Asamblea; en los demás casos, la misma ha consistido en una simple sugerencia al Gobierno para que sea éste quien elabore e impulse el proyecto de ley correspondiente. Durante este tiempo, en fin, el PSOE ha detentado el poder en el Gobierno central durante las legislaturas segunda a quinta y octava y novena (1982-1996, Gobiernos presididos por González; y 2004-2011, Gobiernos presididos por Rodríguez Zapatero), mientras que el PP lo ha hecho durante las legislaturas sexta, séptima y décima (1996-2004, Gobiernos presididos por Aznar; y de diciembre de 2011 hasta la fecha, Gobierno de Mariano Rajoy $\left.^{26}\right)$. Por su parte, el PSOE de Murcia ha controlado la mayoría absoluta de la Asamblea de esta Comunidad Autónoma hasta mayo de 1995, fecha en la que

- Estímulo de la iniciativa legislativa del Gobierno de la Nación sin adjuntar texto sobre modificación de la Ley del Indulto para cargos públicos (BOAR núm. 38, de 15-04-16).

B) Adjuntando texto:

- Estímulo de la iniciativa legislativa del Gobierno de la Nación, adjuntando proyecto de ley, sobre aprovechamiento sostenible del Acueducto Tajo-Segura. (BOAR núm. 99, de 03-02-10).

- Estímulo de la iniciativa legislativa del Gobierno de la Nación, adjuntando proyecto de ley, para la modificación de la Ley 22/2009, de 18 de diciembre, por la que se regula el sistema de financiación de las Comunidades Autónomas de régimen común y Ciudades con Estatuto de Autonomía. (BOAR núm. 143, de 28-03-2011).

- Estimulo de la iniciativa legislativa del Gobierno de la Nación, adjuntando proyecto de ley, para el equilibrio y la igualdad en la financiación autonómica que modifica la ley 22/2009, de 18 de diciembre, por la que se regula para la regulación del sistema de financiación de las Comunidades Autónomas de régimen común y Ciudades con Estatuto de Autonomía (BOAR núm. 69, de 01/01/2013).

- Estímulo de la iniciativa legislativa del Gobierno de la Nación, adjuntando proyecto de ley, sobre relación de los bijos con los progenitores en los casos de ruptura de la convivencia familiar, (BOAR núm. 90, de 21/06/2013).

25 Datos cerrados a 23 de mayo de 2016, Portal Web de la Asamblea Regional de Murcia: Congreso de los Diputados: http://www.ambleamurcia.es.

26 A partir de la celebración de las elecciones generales de 20 de diciembre de 2015, el Gobierno «cesante» de Mariano Rajoy ha continuado en funciones, situación que se prolongará hasta la toma de posesión de un nuevo Gobierno (artículo 101.2 CE). El Real Decreto 184/2016, de 3 de mayo, ha disuelto las Cortes elegidas el 20 de diciembre de 2015 ha convocado elecciones para el 26 de junio del presente año. 
un claro cambio de tendencia trasladó esta mayoría al PP, el cual la conservó sin fisuras hasta las pasadas elecciones autonómicas de $2015^{27}$.

A partir de tales datos, la indagación sobre el comportamiento de esta figura —el estímulo de la iniciativa legislativa del Gobierno de la Nación- en la Comunidad Autónoma de Murcia nos muestra distintos aspectos de la misma que, en consonancia con lo dicho más arriba, procede subrayar:

(i) Diez de estas catorce solicitudes lo son «sin adjuntar texto articulado» $\mathrm{y}$ su práctica evidencia que se tramitaron y fueron aprobadas habitualmente como moción. Ello se corresponde bastante bien con lo que ya sabemos que dice el artículo 148.2 RARM: «En el supuesto tercero del artículo 147 (sugerencia sin texto para que el Gobierno central lo elabore)... se realizará conforme a lo dispuesto para las mociones y siempre en Pleno». En un alto número de estos casos — siete sobre diez- no parece que haya habido ningún inconveniente que impida que la mencionada movilización del Gobierno central la acometa una Asamblea autonómica de su mismo color político: en cinco de estas ocasiones (1989, trabajadores agrícolas; 1992, horarios comerciales; 1994, protección de la familia; 1994, uniones de hecho; 1995, Plan Hidrológico Nacional) es una Asamblea con mayoría PSOE la que adopta la decisión de solicitar de un Gobierno central también controlado por el PSOE — los cuatro Gobiernos de Felipe González- que ponga en marcha una cierta actividad propia de la esfera legislativa del Estado; y en las otras dos (2012, homologación universitaria; 2016, uniones de hecho) es una Asamblea con mayoría del PP (absoluta en el primer caso y simple en el segundo) la que presenta solicitudes a un Gobierno del mismo color político. ¿Cómo es ello posible? Pues porque en todos estos casos la figura que comentamos es percibida por sus actores más como una moción que como un auténtico estímulo de la iniciativa legislativa. No en vano no hay aquí un texto articulado, y lo único que se tiene delante a la hora de decidir es una mera resolución parlamentaria orientada a pedirle al Gobierno de la Nación — como en tantas mociones aprobadas por la Asamblea a la conclusión de un debate cualquiera- que se tome interés por impulsar determinada cuestión u objeto. En estas condiciones, pues, identificado y casi confundido con la moción, el estímulo de la iniciativa legislativa del Gobierno central pierde buena parte de su carácter y, por lo tanto, de su trascendencia.

${ }^{27}$ De los 45 diputados elegidos en las elecciones autonómicas de 2015, el PP obtuvo 22, el PSOE 13, Podemos 6 y Ciudadanos 4. El candidato del PP, Pedro Antonio Sánchez, fue elegido Presidente de la Comunidad Autónoma de Murcia con el voto a favor de los 22 diputados del PP y los 4 de Ciudadanos. 
(ii) A confirmar que esto es así viene el hecho de que, en determinadas ocasiones, tal propuesta aparezca rechazada como estímulo de la iniciativa del Gobierno de la Nación y, sin embargo, aprobada como «moción con modificaciones». Ese es el caso, entre otros, de la solicitud de iniciativa legislativa sobre protección por desempleo agrario eventual, dejada decaer como tal y, en cambio, adoptada como «moción consensuada de todos los grupos» (BOAR núm. 228, de 04-05-87); de la referida al reconocimiento de la aparcería como terraje, retirada como estímulo de la iniciativa legislativa del Gobierno y, sin embargo, aprobada como «moción con modificaciones» (BOAR núm. 62, de 06-06-88); o de la relativa a ciertas actuaciones relacionadas con la población inmigrante, rechazada como impulso de iniciativa gubernamental y aprobada, no obstante, como «moción con modificaciones» (BOAR núm. 172, de 20-06-94).

(iii) $\mathrm{Al}$ margen de lo anterior, un dato no menos significativo es el que nos revela, bien que en otro orden de cosas, que entre marzo de 1995 y marzo de 2006 la Asamblea Regional de Murcia, dominada por mayoría PP, no adoptó ninguna solicitud dirigida a estimular la iniciativa legislativa del Gobierno PP, de su propio color. Aquí la práctica empieza a mostrar sus connotaciones de partido. Aunque su desvirtuación como mera moción parlamentaria permitiera - lo hemos visto - ciertas licencias durante la etapa PSOE, durante la etapa PP controlada por el Gobierno Aznar (sexta y séptima legislaturas) ni siquiera con ese desdibujado carácter se consiente que una eventual solicitud de iniciativa legislativa dirigida al Gobierno central pueda adquirir visos de presión —no digamos de oposición - frente al propio partido que gobierna en España.

(iv) Son dos de las cuatro oportunidades en las que la solicitud se produce «adjuntando texto articulado» (en 2010, intento de bloqueo del trasvase TajoSegura por el Estatuto de Castilla-La Mancha; y en 2011, sistema de financiación de las Comunidades Autónomas) las que nos acercan a ese contexto donde es posible advertir con mayor claridad que esta figura opera más como un arma de enfrentamiento en los litigios que oponen a mayoría y oposición dentro de la propia Comunidad Autónoma que como un auténtico instrumento para el estímulo legislativo del Gobierno de la Nación.

En la primera de estas ocasiones, el Grupo popular de la Asamblea presentó una iniciativa autonómica de modificación de Ley 10/2001, reguladora del Plan Hidrológico Nacional dirigida al Gobierno de la Nación a fin de que fuera éste —en este caso el Gobierno socialista de Rodríguez Zapatero- el que tuviera que instar del Congreso de los Diputados, a través de un proyecto de ley, su tramitación, bien que, en el fondo, lo presentara con la secreta esperanza, casi con la absoluta seguridad, de que ese impulso no se iba a producir y de que, en consecuencia, tal actitud elusiva del Gobierno Zapatero se volvería contra el 
propio Grupo socialista de la Asamblea que había roto el consenso ${ }^{28}$. La retirada del proyecto de Estatuto de Castilla-La Mancha en abril de 2010 zanjó, no obstante, el problema e hizo que la cuestión de fondo suscitada por el caso anterior quedara agotada, pero la eficacia distorsionada de este estímulo potencialmente utilizable como instrumento de «oposición contra la oposición» quedó claramente de manifiesto.

La segunda de las ocasiones a las que inicialmente aludimos ha tenido que ver con las conocidas diferencias que la Comunidad Autónoma de Murcia mantiene con el modelo de financiación vigente en España desde 2009, desacuerdo que le llevó a utilizar el estímulo autonómico de la iniciativa legislativa del Gobierno central que el artículo 87.2 CE le permite para intentar cambiarlo. El problema aquí para el Partido Popular, gobernante en la Región, residía en saber de antemano que canalizar esa iniciativa a través del Congreso de los Diputados suponía contar desde ya con su derrota dado que el Gobierno central socialista no estaba por las medidas que a la Comunidad Autónoma de Murcia le interesaba introducir en dicho modelo. En consecuencia, la solución para el Gobierno popular autonómico consistió en no plantear tal estímulo ante el Congreso de los Diputados sino ante el Gobierno de la Nación con el nada disimulado interés de alcanzar así un triple objetivo: a) marcar en el contexto del Estado de las Autonomías cuál era la posición de Murcia sobre el sistema de financiación en vigor; b) convertir esta actuación en un mecanismo explícito de oposición frente al Gobierno central (especialmente frente al Presidente del Gobierno en cuanto líder nacional del partido contrincante) y a sus —en el concepto de la Comunidad Autónoma de Murcia- equivocados criterios sobre dicha materia;

${ }^{28}$ El temor a la eventual aprobación por el Congreso de los Diputados del proyecto de reforma del Estatuto de Autonomía de Castilla-La Mancha, cuyo texto ponía fecha de caducidad al trasvase Tajo-Segura, hizo que a principios de 2009 los Grupos popular y socialista de la Asamblea Regional de Murcia pactaran la presentación como iniciativa consensuada y conjunta de una proposición de ley de iniciativa autonómica dirigida al Congreso de los Diputados y orientada a lograr una modificación de la Ley 10/2001, reguladora del Plan Hidrológico Nacional, a fin de asegurar así desde dicho texto la continuidad del trasvase frente a las citadas pretensiones del Estatuto castellano-manchego. Esta proposición apareció, sin embargo, publicada en el BOAR núm. 59, de 10 de febrero de 2009, como iniciativa unilateral del Grupo socialista el cual se adelantó — en mitad de ciertos rifirrafes entre Grupos- a depositarla ante la Mesa de la Asamblea bajo el título de Iniciativa legislativa ante el Congreso de los Diputados $n .^{\circ} 1$, sobre Proposición de Ley de modificación de la Ley 10/2001, del Plan Hidrológico Nacional, en relación con el Acueducto Tajo-Segura. La respuesta del Grupo popular frente a dicha actuación unilateral del Grupo socialista se tradujo, amén de en el reiterado entorpecimiento a la posibilidad de que la propuesta socialista se debatiera desde ya (consiguió atrasar hasta seis veces el plazo de presentación de enmiendas), en el depósito el 11 de enero de 2010 de la iniciativa que comentada (vid., su texto en BOAR núm.98, de 15 de enero de 2010). 
c) y, además, hacerlo servir en el marco de sus enfrentamientos con la oposición socialista presente en la Asamblea autonómica al permitirle contestar a cada censura recibida desde aquélla con coste económico que las responsabilidades estaban en su propio partido cuyo Gobierno central no atendía los impulsos que — como éste- hubieran permitido mejorar el modelo y, con ello, la disponibilidad de los recursos necesarios ${ }^{29}$. La contestación del Gobierno a tal propuesta, como era de esperar, nunca se produjo, pero su virtualidad como instrumento de oposición, esta vez doble, a la vez frente al Gobierno de la Nación y frente a la oposición socialista interna en la Comunidad, quedó de nuevo probada. No sólo no se esperaba que hubiera respuesta sino que más bien se contaba interesadamente con ello, más aún en una cuestión tan litigiosa y controvertida como ésta en la que todos los medios para operar valían.

(v) La aparición de otro escenario diferente tras las elecciones autonómicas de 2015 —el PP gobierna pero no ostenta la mayoría absoluta de la Asambleaha permitido que sea esta vez la oposición (PSOE, Podemos y Ciudadanos) la que haya actuado la iniciativa legislativa autonómica ante el Gobierno central como arma política, aprobándose recientemente una solicitud — sin texto adjuntodirigida al Gobierno en funciones de Mariano Rajoy para la modificación de la Ley del Indulto para cargos públicos (BOAR núm. 38, de 15-04-16) ${ }^{30}$.

En síntesis, la práctica de esta figura nos sitúa, pues, ante una doble desvirtuación de su sentido a la que no es ajeno el hecho de que carezcamos de un procedimiento normado — por poco exigente que éste sea — capaz de reforzar su lógica institucional marcando mejor su finalidad más ortodoxa. Con excesiva frecuencia, o bien esta figura diluye su identidad en la de una simple moción parlamentaria sin mayor trascendencia dirigida al Gobierno para estimularle a actuar en un cierto sentido, lo que no anima a éste a prestarle mayor atención, o bien se la actúa — desprendida totalmente de su intención impulsora- como un hábil mecanismo a utilizar en su estrategia de oposición con el que poder trasladar la responsabilidad de determinadas carencias a la fuerza política (central y/o autonómica) de distinto color que esté operando en ambos espacios, lo cual

29 La propuesta fue planteada como «Estímulo de la iniciativa legislativa del Gobierno de la Nación, adjuntando proyecto de ley, para el equilibrio y la igualdad en la financiación autonómica que modifica la Ley 22/2009, de 18 de diciembre, por la que se regula el sistema de financiación de las Comunidades Autónomas de régimen común y Ciudades con Estatuto de Autonomía», y debatida en el Pleno de la Asamblea de 23 de marzo de 2011. Su texto puede verse en el BOAR núm. 143, de 28 de marzo de 2011, su remisión al Gobierno se hizo mediante oficio del propio 23 de dicho mes.

${ }^{30}$ La aprobación de este estímulo de la iniciativa legislativa del Gobierno, que fue propuesto por el grupo parlamentario socialista, no aparece publicada esta vez en el apartado «Mociones o proposiciones no de ley» sino en el de «Acuerdos y resoluciones». 
supone un claro incumplimiento del principio de lealtad constitucional, principio que, en palabras de Biglino Campos, «...no sólo impone al Estado y a las Comunidades Autónomas el deber de mantenerse dentro de sus propias competencias...El deber de lealtad impone también la obligación ejercer las propias funciones de una determinada mantera. En efecto, éstas no deben ser practicadas en una situación de enfrentamiento respecto a la otra entidad territorial sino, al contrario, teniendo en cuenta también sus intereses ${ }^{31}$. En la desembocadura de tales defectos, la identidad del estímulo de la iniciativa legislativa del Gobierno de la Nación padece, en fin, de forma considerable.

\section{IDEAS PARA UNA PROPUESTA DE LEGE FERENDA: LA NECESIDAD DE IMPONER UNAS MÍNIMAS OBLIGACIONES AL GOBIERNO CENTRAL IMPULSADO POR ESTA VÍA}

La conclusión principal que se deduce del largo recorrido argumental anterior es que la regulación que el legislador ha dado a esta forma de impulso de la iniciativa legislativa de ley estatal prevista por el artículo 87.2 CE, el estimulo de la iniciativa legislativa del Gobierno de la Nación, es notoriamente deficiente sobre todo en aquel de sus aspectos que deja literalmente en blanco la existencia de cualquier tipo de obligación a cargo del Gobierno respecto del estímulo que acaba de recibir. Es ese vacío normativo el que le permite al Ejecutivo no tener que darse siquiera por enterado de que tal iniciativa autonómica ha llegado a sus manos. Y es, a su vez, la seguridad de que las cosas se van a desarrollar de este modo la que anima a las Comunidades Autónomas a desconocer el verdadero sentido — la verdadera identidad — de esta figura, desvirtuándola de la doble manera que ya conocemos.

Nada de esto parece importar, porque como el Derecho no impone ningún deber al Gobierno que le obligue a prolongar el proceso con actos propios de comunicación, acuse de recibo, aceptación o rechazo, la ausencia de toda actuación por su parte no parece lesionar norma alguna. Y, de hecho, no la lesiona. No obstante, va de suyo que ésta no es la situación ideal y que si hemos convenido que la causa real del fiasco que esta vía padece en la práctica reside en la inexistencia de una consecuencias procesales necesarias que anudar al comportamiento del Gobierno tras el hecho de haber recibido éste el impulso autonómico, tendremos que concordar también que el Derecho debería taponar esa fisura estableciendo unas

31 Biglino Campos, P. (2004): «La lealtad constitucional en el Estado de las Autonomías», en Revista Jurídica de Castilla y León, núm. Extra 1 (Ejemplar dedicado a: 25 años de Constitución), p.68. 
medidas que permitan reintegrar este instituto a su verdadero sentido y a su más cierta eficacia. Es lo que, de lege ferenda, hacemos a continuación.

En esta tarea no parece sensato, sin embargo, caminar en ninguna de las dos direcciones siguientes:

No sería correcto diseñar esta zona vacía del proceso, la que se desarrolla en sede del Gobierno, como un procedimiento milimétrico y cerrado en el que todo apareciera pautado y previsto cuando está claro que el Gobierno debe conservar la libertad de ser él quien precise lo que quiere concretar y hasta dónde lo quiere concretar.

Y tampoco parecería adecuado intentar constreñir al Gobierno con un procedimiento que le cerque u obligue más allá de lo debido; que el Ejecutivo deba prolongar su recepción del estímulo autonómico con actos propios no significa, en nuestro sentir, que la previsión de tales actos no pueda consistir en mínimos o no se pueda satisfacer de un modo tendencialmente formal; para decirlo de la manera más clara, que el Gobierno esté en la obligación de hacerse cargo del impulso autonómico que le llega no supone que no pueda deshacerse de él mediante la simple afirmación de que dicha medida no se compadece, en este caso, con su programa legislativo, razón más que suficiente para desecharla. Pero este acto sí debe de existir.

Sentadas ambas premisas, el diseño de mínimos que, de lege ferenda, cabe establecer respecto de esta figura es el siguiente:

a) Una vez recibido por el Gobierno desde una Comunidad Autónoma el estímulo de su iniciativa legislativa, aquél debería venir obligado a incluir la cuestión en el orden del día de un Consejo de Ministros a celebrar en fecha nunca posterior a los treinta días siguientes al de su registro de entrada; si se decide que ha de pasar antes por la Comisión de Secretarios de Estado y Subsecretarios - lo que no siempre debería ser preciso si el Gobierno decide prescindir de dicho trámite_- debería incluírsele siempre en el «índice rojo» a efectos de que al Gobierno le llegue como una cuestión informada pero nunca prácticamente decidida.

b) El Gobierno debe acusar recibo de dicho documento a la Comunidad Autónoma remitente, a la que podrá recabar, en su caso, aquellos informes y materiales adicionales que considere oportunos.

c) Llegado el día del Consejo de Ministros, el Gobierno debe resolver necesariamente sobre la solicitud autonómica en un sentido o en otro, esto es, aceptando ese estímulo y procediendo a impulsar la posterior tramitación del proyecto de ley en los términos que ya conocemos, o rechazándolo de plano. 
d) Tanto la aceptación con el rechazo del estímulo deberán estar motivados, bien que en el caso del rechazo pueda y deba bastar como razón suficiente para hacerlo — según vimos - la alegación por parte del Gobierno de la incompatibilidad de éste con su programa legislativo o incluso con su criterio de fondo sobre la materia.

e) El Gobierno deberá venir obligado a dar traslado de su resolución a la Comunidad Autónoma correspondiente en el plazo que se fije.

f) En fin, el Gobierno también debería tener que comunicar a la Asamblea proponente la remisión del proyecto a la Mesa del Congreso, por cortesía institucional y porque ello permitiría a aquella Asamblea comprobar de qué manera el Gobierno ha atendido su solicitud (por ejemplo, si hay o no modificaciones al texto por ella enviado en su momento) y llevar a cabo el seguimiento de la tramitación del proyecto por ella impulsado en las Cortes.

Se trata, a la postre, como el lector habrá advertido, de obligaciones estrictamente formales, respetuosas con la libertad de la que el Gobierno debe disponer, pero suficientes para evitar el absurdo que supone la existencia de una figura jurídica vacía de Derecho como la que, en este caso, el constituyente ha diseñado.

\section{BIBLIOGRAFÍA}

Biglino Campos, P. (2004): «La lealtad constitucional en el Estado de las Autonomías», en Revista Jurídica de Castilla y León, núm. Extra 1 (Ejemplar dedicado a: 25 años de Constitución), p.68.

Cascajo Castro, J. L. (1992): «La forma parlamentaria de Gobierno en el sistema constitucional español, en Revista Vasca de Administración Pública, núm. 34 , pp. 13 y ss.

DORREGo de CARlos, A. (1988): «Artículo 88: Iniciativa legislativa gubernamental», en O. Alzaga Villaamil (director), en Comentarios a la Constitución española de 1978, Madrid, Cortes Generales-Edersa, pp. 289-353.

EliA, L. (1951): «Il governo come comitato direttivo del Parlamento», en Rivista Civitas, núm. 4, pp. 59 a 66.

García Escudero-Márquez, P. (2000): «La iniciativa legislativa en la Constitución española de 1978», en Revista Española de Derecho Constitucional, núm. 59, p. 75.

García-Escudero Márquez, P. (1999): «La prioridad en la tramitación parlamentaria de los proyectos de ley», en Teoría y realidad constitucional, núm. 3, pp. 125-164. 
García-Escudero Márquez, P. (2000): La iniciativa del Gobierno, Madrid, Centro de Estudios Políticos y Constitucionales.

García Martínez, M. A. (1998): «Las participación de las Comunidades Autónomas en el procedimiento legislativo estatal», en Revista de la Facultad de Derecho de la Universidad Complutense de Madrid, núm. 22.

GARrido MAYOL, V. (2010): Las garantías del procedimiento prelegislativo: la elaboración y aprobación de los proyectos de ley, Valencia, Tirant lo Blanch, pp. 34-44.

Garrorena Morales, A. (1980): El lugar de la ley en la Constitución española, Madrid, Centro de Estudios Constitucionales, pp. 114-115.

Gerpe Landín, M. (1980): «Relaciones entre las Cortes Generales y las Asambleas de las Comunidades Autónomas. La iniciativa legislativa de las Comunidades Autónomas en la Constitución española de 1978», en M. A. Aparicio (coordinador), Parlamento y sociedad civil, Barcelona, Universidad de Barcelona, p. 167.

Herrero Lera, M. (1988): «Artículo 87: Iniciativa legislativa», en O. Alzaga Villaamil (director), Comentarios a la Constitución española de 1978, Madrid, Cortes Generales-Edersa, pp. 209-240.

Lavilla Rubira, J. J. (1990): «Las proposiciones de ley remitidas por las Comunidades Autónomas al Congreso de los Diputados», en Revista Española de Derecho Constitucional, núm. 28.

Lucas Verdú, P. (1977): «Iniciativa legislativa», en Nueva enciclopedia jurídica, Barcelona, Seix, vol. XII, pp. 623-627.

Martín Casals, M. y Viver Pi-Sunyer, C. (1990): «¿Quién redacta las leyes? Los modelos de redacción «concentrada» y de redacción «difusa» de los proyectos de ley», en Revista de las Cortes Generales, núm. 21, p. 8.

Merino Merchán, J.F. (1984): «La potestad de iniciativa legislativa de las Comunidades Autónomas», en Organización territorial del Estado (Comunidades Autónomas), Madrid, Instituto de Estudios Fiscales.

Mollinedo Chocano, J.J. (1998): «La iniciativa legislativa de las Comunidades Autónomas», en El procedimiento legislativo: V Jornadas de Derecho Parlamentario, Madrid, Congreso de los Diputados.

Montesquieu (1748): De l'esprit des lois, libro XI, cap. VI.

Navarro Ruiz, J.C. (2014): «La iniciativa legislativa de los parlamentos autonómicos ante el parlamento estatal», en Representación politica y parlamentarismo multinivel, Valencia, Tirant lo Blanch, núm. 59.

Oтto y PARdo, I. (1980): «La posición constitucional del Gobierno», en Documentación Administrativa, núm. 188, p. 178.

Pérez Francesch, J.L. (1996): El Gobierno, Madrid, Tecnos, pp. 29-30.

Punset Blanco, R. (1982): «La iniciativa legislativa en el ordenamiento español», en Revista de Derecho Político, núm. 14, p. 78. 
SANZ PÉREZ, A.L. (2015): «La importancia del procedimiento preparlamentario de elaboración de un proyecto de ley o las preguntas sin respuesta», en Revista Aranzadi Doctrinal, núm. 4, pp. 125-132.

Title:

The exercise of the legislative initiative of the Autonomous Communities before de national Government. Singularity, deficits and proposals de lege ferenda

\section{Summary:}

I. INTRODUCTION. II. WHAT THE LAW SAYS ABOUT IT: 2.1 The autonomic phase. Articulated or unarticulated formulation of the impulse of the Assemblie of the Autonomous Community. 2.2 State phase and the action (or inaction) of the national Government: A) Regulatory framework. B) The assumption of the autonomic impulse by the Government: the "praevios pass» of the Council of Ministers. C) Excursus: advantages and disadvantages that can result from this type of autonomic initiative. Considerations about the supposed primacy of the governmental legislative initiative. III. WHAT THE LAW DOES NOT SAY. THE FACTS AS «PASSIVE»OF THIS FIGURE: 3.1 A cause that still belongs to the realm of law: the absurdity that implies that a power granted by the Constitution to autonomics parliaments did not follow any procedure. 3.2. And two consequences of that nonsense: A) An unavoidable sequel: the almost total disengagement of the Government of the Nation. B) And an already proven dysfunctional practice: the use of this figure diverted for different purposes than those you are supposed to. Recourse to the «case method». IV. PROPOSALS DE LEGE FERENDA. V. BIBLIOGRAPHY.

\section{Resumen:}

Las Comunidades Autónomas pueden, porque así se lo autoriza el artículo 87.2 de la Constitución, iniciar leyes estatales tanto ante el Gobierno de la Nación como ante el Congreso de los Diputados. Sin embargo, los escasos trabajos que se ocupan de la iniciativa legislativa autonómica se centran casi exclusivamente en la segunda de las vías acogidas por aquel artículo, sin que prácticamente se haya llevado 
a cabo ningún comentario teórico que trate de dar sentido, hacer la crítica y elaborar unas ciertas garantías a la utilización de la vía ante el Gobierno. El ejercicio de esta modalidad de iniciativa legislativa regional abre todo un panel de cuestiones a tratar, algunas más sustantivas, como el saber el por qué de dicha previsión (¿para qué estimular la puesta en marcha de la ley ante un órgano que no es un legislador?), y otras estrictamente procedimentales (principalmente referidas a la tramitación que han de seguir, en el seno del Gobierno, las solicitudes de proyectos de ley remitidas por los parlamentos regionales), a todas las cuales el presente estudio trata de dar respuesta. Con el fin de ordenar todas estas cuestiones es útil distinguir dos fases claramente diferenciadas a través de las cuales se articula la actuación de este estímulo de la iniciativa legislativa gubernamental. La primera de estas fases tiene lugar en el seno de los parlamentos regionales de acuerdo con lo previsto en sus respectivos reglamentos parlamentarios, y se concreta en la aprobación por tales Cámaras de la remisión al Gobierno de una propuesta -articulada o no- de proyecto de ley. La segunda fase se desarrolla en el seno del Gobierno, el cual, si decide discrecionalmente atender la solicitud remitida por una Asamblea autonómica, iniciará el procedimiento de elaboración, aprobación y posterior remisión a las Cortes del proyecto de ley previsto en nuestro ordenamiento jurídico. De especial interés resulta, a este respecto, analizar las consecuencias de la incomprensible ausencia de un mínimo procedimiento que prolongue la actuación de la iniciativa autonómica con algún tipo de actuación necesaria a cargo del Gobierno de la Nación, lo cual viene a reducir la facultad atribuida por la Constitución a las Asambleas de las Comunidades Autónomas que nos ocupa a un "vacío" ayuno de toda entidad jurídica, razón por la cual nos permitimos proponer algunas medidas de lege ferenda con el fin de reintegrar este instituto a su verdadero sentido y a su más cierta eficacia.

\begin{abstract}
:
The article 87.2 of the Spanish Constitution assigns to the Assemblies of the Autonomous Communities the power to initiate state laws, power that can exercise before the National Government or the Chamber of Deputies. However, few studies dealing with the regional legislative initiative focusing exclusively on the second of the routes received by that article. Practically it has not been carried out any theoretical commentary try to make sense, to criticize and develop a certain guarantees to the use of the road with the Government. The procedure for exercising the request to government bills opens some substantive problems (for example, why should stimulate the
\end{abstract}


implementation of the law before a body which is not a legislator?), and others of a procedural nature (mainly concerning the processing to be followed within the Government requests for bills approved by regional parliaments), all of which this study try to respond. For this, it examines each of the two phases through which the exercise of this regional initiative articulates. The first phase takes place within regional parliaments in accordance with the provisions of their respective parliamentary rules in order that such chambers approve the referral to the State Government a proposed bill. The second phase develops within the Government, which, if it decides to grant the request submitted by a regional Assembly, it will initiate the procedure for preparation, approval and subsequent submission to the state Parliament of the bill. We examined its regulatory framework, the assumption of the regional impulse by the Government (the "previous pass" of the Council of Ministers), or the advantages can have this form of the regional legislative initiative against the other form of regional legislative. Of particular interest is analyzed the consequences of the incomprehensible absence of a minimum procedure to prolong the action of the regional initiative with some kind of action to be taken by the Government of the Nation, which has the result of reducing to a "vacuum" the statutory provision of article 87.2 of the Constitution, for which reason it is proposed here some further measures de lege ferenda that are desirable in order to this institution might better fulfil their purposes in an efficient manner.

\section{Palabras clave:}

Iniciativa legislativa, Comunidades Autónomas, Gobierno, proyecto de ley, ley.

\section{Keywords:}

Legislative initiative, Autonomous Communities, Government, bill, law. 
